\title{
PRDM16 inhibits cell proliferation and migration via epithelial to mesenchymal transition by directly targeting pyruvate carboxylase in papillary thyroid cancer
}

\section{Wan-Lin Liu}

Fudan University Shanghai Cancer Center

\section{Qing Guan}

Fudan University Shanghai Cancer Center

\section{Duo Wen}

Fudan University Shanghai Cancer Center

\section{Ben Ma}

Fudan University Shanghai Cancer Center

\section{Wei-Bo Xu}

Fudan University Shanghai Cancer Center Jia-Qian Hu

Fudan University Shanghai Cancer Center

\section{Wen-Jun Wei}

Fudan University Shanghai Cancer Center

\section{Duan-Shu Li}

Fudan University Shanghai Cancer Center

\section{Yu Wang}

Fudan University Shanghai Cancer Center

\section{Jun Xiang}

Fudan University Shanghai Cancer Center

\section{Tian Liao}

Fudan University Shanghai Cancer Center

Qinghai Ji ( $\sim$ jq_hai@126.com )

Fudan University Shanghai Cancer Center

\section{Research}

Keywords: papillary thyroid cancer, PRDM16, pyruvate carboxylase, epithelial to mesenchymal transition, metastasis 
Posted Date: June 17th, 2020

DOl: https://doi.org/10.21203/rs.3.rs-35587/v1

License: (c) (i) This work is licensed under a Creative Commons Attribution 4.0 International License. Read Full License

Version of Record: A version of this preprint was published at Frontiers in Cell and Developmental Biology on November 2nd, 2021. See the published version at https://doi.org/10.3389/fcell.2021.723777. 


\section{Abstract \\ Background}

PRDM16 (known as MEL1), a member of PR domain zinc finger family, has been implicated in multiple biological processes including cancers. It is not clearly yet whether PRDM16 is involved in tumor progress of papillary thyroid cancer (PTC).

\section{Methods}

We identified PRDM16 expression level in PTC tissues by qRT-PCR and analyzed its relationship with clinical characteristics in both Fudan University Shanghai Cancer Center (FUSCC) cohort and TCGA cohort. We tested the function of PRDM16 in PTC cells both in vivo and in vitro. We found direct downstream target of PRDM16, pyruvate carboxylase (PC) by RNA-sequencing, rescue experiments, Luciferase assay and Chromatin Immunoprecipitation assay.

\section{Results}

PRDM16 was downregulated in papillary thyroid cancer tissues and was significantly related with lymph node metastases and extrathyroid extension in both FUSCC and TCGA cohorts. Overexpression of PRDM16 could attenuate proliferation and migration of PTC cells via inhibiting epithelial to mesenchymal transition process. PC was upregulated in papillary thyroid cancer tissues. Knockdown of PC could inhibit proliferation and migration in TPC-1 and K1 cells. The repression effect on cell proliferation and migration from PRDM16 was PC dependent. PRDM16 could directly bind to PC promoter and inhibited its expression at transcription level. Moreover, the mRNA expression level of PRDM16 and PC was negatively related in human PTC tissues.

\section{Conclusions}

In conclusion, PRDM16 exhibited anti-tumor effect and EMT inhibition function in PTC by directly binding with PC promoter. PRDM16 may be a novel therapeutic target in papillary thyroid cancer.

\section{Background}

Thyroid cancer is the most common type of endocrine malignancy. Since the 1970s, its incidence has increased three-fold over the past three decades all over the world(1). Based on recent data, thyroid cancer is the fifth most common cancer in women in the USA(2). Papillary thyroid carcinoma comprises eighty percent of all thyroid cancer, named for their papillary histological architecture (3). Worldwide trends in thyroid cancer incidence have been largely driven by an increase in PTC, followed by follicular, medullar and anaplastic histological subtypes (4). Though the prognostic of papillary thyroid cancer is 
usually excellent with a 5-year survival rate exceeding $95 \%$ (5) and a 10-year survival rate of more than $90 \%$ (6), about $20 \%$ of PTC patients still develop recurrent disease, including local cervical recurrences and distant metastases (7), which could be incurable and fatal (8). Prognostic factors of recurrence for PTC include age at diagnosis, histological subtypes, extrathyroidal extension (ETE), lymph node metastases (LNM) and tumor-node-metastasis (TNM) stage (6). Besides, several molecular genetic alterations have been studied as putative predictive markers in papillary thyroid cancer. For example, $\mathrm{BRAF}^{\mathrm{V} 600 \mathrm{E}}$ gene mutation is widely demonstrated to be associated with ETE, LNM, recurrence and mortality $(3,9-11)$ are considered to be a potential target for treatment of PTC $(12,13)$. The underlying factors and mechanisms for the aggressiveness of PTC remain unclear.

The positive regulatory domain containing 16 (PRDM16), also known as MDS1/EVI1-like gene 1(MEL1), is a member of PR domain zinc finger family. The N-terminal PR domain is characteristic of PRDM family which consists of seventeen members known currently in the human body, named PRDM1 to PRDM17 (14). PRDM16 gene is located on human chromosome 1, encoding a protein of 1275 amino acids. It was first discovered by Naomi Mochizuki, et al. in acute myeloid leukemia (AML) and myelodysplastic syndrome study in 2000 (15). PRDM16 gene is a crucial regulator of the cell-fate switch between brown adipose tissue and skeletal myoblasts (16-18). PRDM16 overexpression was demonstrated to be a compelling poor prognostic marker of pediatric $\operatorname{AML}(19,20)$. It could suppress mixed lineage leukemia (MLL) through its intrinsic histone methyltransferase activity of the PR domain (21). Apart from the study in hematologic neoplasm, recent researches have explored controversial functions of PRDM16 gene in solid cancers. Mami Takahata, et al. (22) demonstrated PRDM16 could inhibit TGF- $\beta$ signal in gastric cancer cells cooperated with SKI. In prostate cancer, PRDM16 has an anti-apoptosis function and may act as an oncogenic role (23). Meanwhile, high methylation status of PRDM16 promoter was demonstrated as potential biomarker for esophageal squamous cell cancer (24) and lung cancers (25). So far, the role of PRDM16 gene in PTC has not been established yet.

In this study, we firstly identified that the expression of PRDM16 was downregulated in tumors from papillary thyroid cancer patients, with significantly lower levels found in PTC patients with lymph node metastasis and extrathyroidal extension. PRDM16 functions as key determinant of pyruvate carboxylase (PC) overexpression and aberrant signaling in PTC cells. Furthermore, PRDM16 could regulate cell proliferation and migration via suppressing epithelia-to-mesenchymal transition (EMT) process. Thus, our findings establish PRDM16 as a previously unsuspected key player and a novel therapeutic target for papillary thyroid cancer.

\section{Methods}

\section{Clinical specimen and data collection}

A total of 110 pairs of PTC tumor and adjacent normal thyroid tissues were obtained from patients who underwent thyroidectomy at the Department of Head and Neck Surgery at Fudan University Shanghai Cancer Center (FUSCC) between 2012 and 2017. The diagnosis of PTC was histopathologically 
confirmed and no patient received preoperative treatment. This study was performed in accordance with the 1964 Helsinki Declaration and its later amendments or comparable ethical standards. It was approved by the Human Ethics Committee/Institutional Review Board of Fudan University Shanghai Cancer Center. Written informed consent was obtained from all 110 patients. The following clinical features were collected respectively from patients' records: age at diagnosis, gender, maximum tumor size, multifocality, extrathyroidal extension, cervical lymph node metastasis and Hashimoto's thyroiditis. All the patients were staged using the 2016 TNM classification of the American Joint Committee on Cancer/International Union Against Cancer (26). We also estimated the level of recurrence for each PTC patient based on 2015 American Thyroid Association (ATA) recurrence risk stratification (27). The resected tissue samples were immediately snap-frozen in liquid nitrogen and stored at $-80^{\circ} \mathrm{C}$ for further use.

A validation cohort from The Cancer Genome Atlas (TCGA) database was identified to confirm the preliminary findings at FUSCC. A total of 382 primary PTC patients with detailed PRDM16 expression, $\mathrm{BRAF}^{\mathrm{V} 600 \mathrm{E}}$ mutation, and clinical data were collected from the updated TCGA database. The TCGA cohort clinical data and the gene expression dataset were available on the website of cBioPortal.

\section{Human PTC Cell Culture}

Three human PTC cell lines, TPC-1, BCPAP and K1, and one normal human thyroid epithelial cell line (Nthy-ori 3 - 1) were used. Nthy-ori 3 - 1 cell line was purchased from Sigma. BCPAP was obtained from the cell bank at Chinese Academy of Sciences (Shanghai, People's Republic of China). TPC-1 and K1 cell lines were purchased from the Cell Bank of University of Colorado. All cell lines were cultured in RPMI1640 medium (GIBCO) supplemented with $10 \%$ heat-inactivated fetal bovine serum (FBS; GIBCO) at $37^{\circ} \mathrm{C}$ in a $5 \% \mathrm{CO}_{2}$ chamber.

\section{Total RNA extraction, reverse transcription and quantitative real-time PCR analysis}

Total RNA was extracted from tissues and cultured cells using TRIzol Reagent (Invitrogen) according to the manufacturer's instructions. RNA purity and concentration were determined by the NanoDrop2000 spectrophotometer. A total of $1 \mu \mathrm{g}$ of RNA was reverse-transcribed using a PrimeScript RT reagent kit (Takara, Dalian, China). For quantitative real-time PCR (qPCR), cDNA was amplified using SYBR Green Premix Ex Taq (Takara, Dalian, China) following the manufacturer's instructions. The primers used for qPCR were listed in Supplementary Table 1. Gene expression was normalized against beta actin mRNA expression in three independent experiments. The relative mRNA expression level were determined by the comparative $\mathrm{Ct}\left(2^{-\Delta \mathrm{Ct}}\right)$ method. The relative PRDM16 expression level for each PTC patient was determined by the ratio of the respective tumor tissue expression level to the average value of the whole 110 adjacent normal thyroid tissues expression level. The 110 enrolled PTC patients were divided into PRDM16 low and high expression group based on the median value of their relative PRDM16 expression level, respectively. 


\section{Genomic DNA Extraction And BRAF ${ }^{\mathrm{V} 600 \mathrm{E}}$ Mutation Analysis}

Genomic DNA was extracted from the aforementioned specimens using the TIAamp Genomic DNA Kit (TIANGEN, Beijing, China) according to the manufacturer's instructions. The DNA template was amplified for analysis of mutations in exon 15 of the BRAF gene using PCR followed by Sanger sequencing by BGI. The primers were as followed:

Forward:5'-TGACTCTAAGAGGAAAGATG-3'

Reverse: 5'-AATACTGGGAACTATGAAAA-3'

\section{Immunohistochemistry Staining}

IHC was carried out according to the manufacture's protocol. Briefly, formalin-fixed and paraffinembedded tissue sections were deparaffinized in xylene and hydrated through descending concentrations of ethanol before being placed in a blocking solution to inhibit endogenous peroxidase activity. The slides were incubated with primary antibodies (rabbit anti-human PRDM16, 1:200 dilution, SAB, USA; rabbit antihuman pyruvate carboxylase, 1:200 dilution, Proteintech, China; rabbit anti-human Ki-67, 1:1000 dilution, Proteintech, China) at $4{ }^{\circ} \mathrm{C}$ overnight. A horseradish peroxidase-conjugated rabbit secondary antibody was added for 1 hour at room temperature, followed by 3,3'-diaminobenzidine (DAB) development (DAB Substrate Chromogen System, Dako Agilent Technologies, Shanghai, China) and hematoxylin and eosin (H\&E) as per standard staining protocol. Slides were fixed and images obtained with the Olympus IX71 inverted microscope using the DP2-BSW Olympus image acquisition software system. The results were confirmed by two experienced pathologists who were blinded to the clinicopathologic data of the patients. The staining results were calculated on the basis of the percentage of tumor cell nuclei stained ( 0 , no staining; $1, \leq 10 \% ; 2,10-50 \% ; 3,>50 \%$ ) and the staining intensity ( 0 , negative; 1 , weak; 2 , moderate; 3 , strong). The overall score was the products of the two staining scores. An overall score of 1-5 designated low expression, and an overall score of 6-9 designated high expression of PRDM16.

\section{Western Blotting Assay}

Protein lysates were obtained from $1 \times 10^{6}$ cultured cells with RIPA buffer and boiled at $100{ }^{\circ} \mathrm{C}$ for 10 minutes. Approximately $20 \mu \mathrm{g}$ protein lysates was extracted from each sample, separated by $10 \%$ sodium dodecyl sulfate-polyacrylamide gel electrophoresis (SDS-PAGE). After being blocked in $5 \%$ non-fat milk at room temperature for 1 hour, the interested protein was probed with primary antibody either against human PRDM16 (1:1000 dilution, Abcam), GAPDH (1:1000, Proteintech), Vimentin (1:1000, Proteintech), E-cadherin (1:1000, Proteintech), N-cadherin (1:1000, Proteintech), MMP3 (1:1000, Proteintech ), PC (1:1000, Proteintech) at $4^{\circ} \mathrm{C}$ overnight, and then incubated with goat anti-rabbit IgG or goat anti-mouse IgG (1:5000 dilution for both; Proteintech) at room temperature for 1 hour; and detected with enhanced chemiluminescence reagents (Thermo Fisher Scientific, Shanghai, China). The bands were visualized 
using 1-step ${ }^{\mathrm{TM}}$ NBT/BCIP reagents (Thermo Fisher Scientific, Rockford, IL, USA) and detected by the Alpha Imager (Alpha Innotech, San Leandro, CA, USA).

\section{Plasmid Construction And Transfection}

The PRDM16 sequence was synthesized and subcloned into GV146 vector (GENECHEM Co., Ltd, Shanghai, China). PC overexpression plasmid was bought from GENECHEM Co., Ltd (Shanghai, China) and GV492 vector was used as a negative control. PC-siRNAs were designed and synthesized by Biotend Co., Ltd (Shanghai, China). The sequences of PC-siRNAs were listed in Supplementary Table 2. The cells were incubated for 48 hours before use in assays. Human pGL3-PC-Promoter and four truncated segments pGL3-PC-promoters for Luciferase assay were constructed by GENEWIZ Co., Ltd (Suzhou, China). Plasmids were transfected into cells using Hieff Trans Liposomal Transfection Reagent (Yeasen, Shanghai, China) according to manufacturer's protocol. We adopted qRT-PCR assay and Western blotting to evaluate overexpression of PRDM16. PC overexpression and knockdown efficiency were tested using qRT-PCR. BCPAP PRDM16-OE and BCPAP ${ }^{P R D M 16-N C}$ cell lines were filtrated from BCPAP cells transfected PRDM16 overexpression plasmids or the negative control vector using $200 \mu \mathrm{g} / \mathrm{ml}$ neomycin and cultured with RPMI-1640 with $100 \mu \mathrm{g} / \mathrm{ml}$ neomycin. The stable cell lines were identified using fluorescence microscope for green fluorescence to ensure the transfection efficiency was over $90 \%$.

\section{Cell Viability Assay}

Cell proliferation was detected using a cell counting kit-8 (CCK-8) assay according to the manufacturer's protocol. Briefly, the cells were seeded into $96-$ well plates at $3 \times 10^{3}$ cells/well. An aliquot of $10 \mu \mathrm{l} \mathrm{CCK-8}$ solution was added to each well and the plate was incubated for 2 hours at $37^{\circ} \mathrm{C}$. At the indicated timepoints, the absorbance at $450 \mathrm{~nm}$ was assessed using a spectrophotometer. For each group, data from five wells were pooled. Each experiment was performed in triplicate.

\section{Migration Assay}

The migration of PTC cells was assayed using $6.5 \mathrm{~mm}$ diameter chambers with $8 \mu \mathrm{m}$ pore filters (Transwell, 24-well cell culture; BD Biosciences). Cells were suspended at $5 \times 10^{4} \mathrm{cells} / \mathrm{ml}$ in serum-free media and then $100 \mu \mathrm{l}$ cell suspension was added to the upper chamber. Subsquently $600 \mu \mathrm{l}$ complete medium was added to the lower chamber. The chambers were incubated for 8 hours at $37^{\circ} \mathrm{C}$ with $5 \%$ $\mathrm{CO}_{2}$. After incubation, the filters were fixed with $4 \%$ paraformaldehyde and stained with $0.5 \%$ crystal violet. The upper surface of the filters was scraped with cotton swabs to remove non-migrating cells. The experiments were repeated in triplicate wells and the number of migrating cells in five high-power fields per filter was counted microscopically at x200 magnification. 


\section{Animal Studies}

Five-week old female BALB/c nude mice were obtained from the Shanghai experimental animal center (Shanghai, China). Briefly, $1 \times 10^{7}$ cells were subcutaneously injected into the right back skin area of $\mathrm{BALB} / \mathrm{c}$ nude mice. The size of tumors was measured by Vernier caliper twice a week. After 15 days, mice were killed and tumor tissues were collected, photographed and examined. Paraffin-embedded tissues were sectioned for IHC analysis. Part of tumor tissue was frozen in liquid nitrogen for following experiments. Animal experiments have been preapproved by the Animal Experimentation Ethics committee of Fudan University Shanghai Cancer Center. All procedures were performed in accordance with the National Institutes of Health Guide for the Care and Use of Laboratory Animals.

\section{RNA-sequencing Data Analysis}

BCPAP and K1 cell lines were transfected with PRDM16 oeverexpressing plasmids. After 48 hours of incubation, total RNA ( $5 \mu \mathrm{g}$ per example) from the two cell lines were isolated. Paired-end sequencing was performed with Illumina Hiseq 150PE at GENEWIZ Co., Ltd (Suzhou, China). For computational analysis of RNA-seq data, sequencing reads were aligned using the spliced read aligner HISAT2, which was supplied with the Ensemble human genome assembly (Genome Reference Consortium GRCh38) as the reference genome. Gene expression level were calculated by the fragments per kilobase of transcript per million mapped reads (FPKM).

\section{Luciferase Reporter Assay}

Luciferase reporter assay was performed using Dual-Luciferase Reporter Assay System (Promega, USA). Human PC promoter region was inserted into a pGL3 basic vector as pGL3-PC-Promoter. Both $100 \mathrm{ng}$ of constructed pGL3-PC-Promoter plasmid and $25 \mathrm{ng}$ Renilla luciferase control plasmid were co-transfected into $5 \times 10^{3}$ cells in 96-well plates. Forty-eight hours later, luciferase activities were measured using the Dual Luciferase Assay Kit (Promega, Madison, WI, USA). Renilla luciferase was used to normalize reporter luciferase activities, which were then rescaled to vector control signals equal to unit 1.

\section{Chromatin Immunoprecipitation (ChIP) Assay}

ChIP assays were performed using SimpleChIP Enzymatic Chromatin IP Kit (Magenetic Beads, Cell Signaling Technology, \#9003). Briefly, K1 cells were cross-linked by $1 \%$ formaldehyde for 10 minutes at room temperature. The cross-link reaction was quenched by glycine and cells were lysed in PBS buffer containing protease inhibitor cocktail. Fragmented chromatin was treated with micrococcal nuclease and subjected to sonication to shear chromatin DNA into fragments with 200-500 base pairs in size. Chromatin immunoprecipitation was performed with rabbit anti-histone $\mathrm{H} 3$ (a technical positive control; 1:50) (sc7160; Santa Cruz Biotechnology), goat anti-PRDM16 antibody (ABIN, 184809; $3 \mu \mathrm{g}$ ), and normal 
rabbit IgG (a negative control; $5 \mu \mathrm{g}$ ) (Cell Signaling Technology). After washing with a series of low and high salt concentration washing buffers, immunoprecipitated DNA fragments were de-crosslinked and purified. Immunoprecipitated DNA was quantified by qRT-PCR using SYBR Green Premix Ex Taq (Takara, Dalian, China) with primers for PRDM16 binding sites in PC promoter (listed in Supplementary Table 3). Fold enrichment was calculated based on the threshold cycle (CT) value of the Ig G control using the comparative CT method.

\section{Statistical analysis}

All statistical analyses were performed using GraphPad Prism 5.0 for windows (La Jolla, California, USA) and SPSS ver.19.0 (SPSS Inc., Chicago, IL, USA). Categorical data was presented with frequencies and percentages. The continuous results were expressed as the mean \pm the standard deviation (SD). Paired Student's t-test was used to compare PRDM16 and PC mRNA expression level in tumor and adjacent normal tissues for each patient. Clinical characteristics were compared using the chi-square and Fisher's exact tests for categorical variables and Student's $t$-test for continuous variables. Mann-Whitney U-test was used for continuous data with no normal distribution. Moreover, univariate and multivariate analyses were performed to determine the risk factors for ETE in PTC in the FUSCC and TCGA cohorts using a logistic regression calculated by odds ratio (OR) and $95 \%$ confidence interval $(\mathrm{Cl})$. A nonparametric receiver operating characteristic (ROC) analysis was performed to calculate the best cutoff value of PRDM16 low expression level for distinguishing tumor tissue and normal tissue. Pearson correlation analysis was used to analyze the correlation between PRDM16 and PC mRNA expression. A $P$-value less than 0.05 was considered significant.

\section{Results}

\section{PRDM16 is downregulated in papillary thyroid cancer patients and correlated with poor outcome}

To evaluate PRDM16 expression in PTC tissue, qRT-PCR and IHC were performed in 110 PTC and matched adjacent thyroid tissue specimens from FUSCC cohort. The results revealed that PRDM16 was transcriptionally downregulated in PTC samples $(P<0.001$, Fig. 1 A). Seventy-five of 110 PTC patients presented lower PRDM16 expression level in tumor tissue than that in paired normal tissue, and only $31.82 \%$ patients had higher PRDM16 expression level in tumor tissue compared to the paired normal tissue (Fig. 1B). IHC analysis ( $\mathrm{P}<0.05$, Fig. 1C) confirmed low PRDM16 protein expression in PTC and high PRDM16 protein expression in normal thyroid tissue specimens.

ROC analysis (Supplementary Fig. 1) identified that the best cutoff value for the relative PRDM16 low expression level was 0.00285 . The area under the ROC curve was $0.682(p=0.001)$. Therefore, when the relative PRDM16 expression level was 0.00285 , it could best distinguish PTC tumor tissue with normal thyroid tissue. 
Furthermore, the correlation of PRDM16 with the clinicopathological characteristics of PTC patients in the FUSCC and TCGA cohorts were analyzed, as shown in Table 1 and Table 2. Low PRDM16 expression was significantly associated with ETE and LNM in both the FUSCC and TCGA cohorts, showing a lower expression level of PRDM16 in PTC with aggressive behaviors. Decreased PRDM16 level correlated with N1b stage ( $P=0.010$ in the FUSCC cohort, $P<0.001$ in the TCGA cohort). The FUSCC cohort also indicated that there was a significant difference in PRDM16 expression among gender $(P=0.017)$, multifocality $(P=0.002)$ and the maximum size of tumor $(P=0.018)$. The low expression group had a larger size of tumor $(1.73 \pm 0.81 \mathrm{~cm})$ compared to the high expression group $(1.41 \pm 0.69 \mathrm{~cm})$.

Additionally, PRDM16 low expression was significantly associated with intermediate and high levels of 2015 ATA risk stratification system, showing a higher possibility of suffering disease recurrence. As for the TCGA cohort, PRDM16 low expression was also correlated with T stage $(P<0.001)$, TNM stage $(P<$ $0.001)$, histological type and BRAF ${ }^{\mathrm{V} 600 \mathrm{E}}$ mutation. 


\begin{tabular}{|c|c|c|c|c|}
\hline Variables & & $\operatorname{Low}(n=55)$ & $\operatorname{High}(\mathrm{n}=55)$ & $\begin{array}{l}P \text { - } \\
\text { value }\end{array}$ \\
\hline \multirow[t]{2}{*}{ Gender } & Female & $46(56.79 \%)$ & $35(43.21 \%)$ & $0.017^{*}$ \\
\hline & Male & $9(31.03 \%)$ & $20(68.97 \%)$ & \\
\hline \multirow[t]{2}{*}{ Age at diagnosis $\llbracket$ years $\rrbracket$} & $<55$ & $46(48.94 \%)$ & $48(51.06 \%)$ & 0.589 \\
\hline & $\geq 55$ & $9(56.25 \%)$ & $7(43.75 \%)$ & \\
\hline \multirow[t]{2}{*}{ ETE } & Yes & $20(68.97 \%)$ & $9(31.03 \%)$ & $0.017^{\star}$ \\
\hline & No & $35(43.21 \%)$ & $46(56.79 \%)$ & \\
\hline \multirow[t]{2}{*}{ Coexistent HT } & Yes & $7(58.33 \%)$ & $5(41.67 \%)$ & 0.541 \\
\hline & No & $48(48.98 \%)$ & $50(51.02 \%)$ & \\
\hline \multirow[t]{2}{*}{ Multifocality } & Unifocal & $25(71.43 \%)$ & $10(28.57 \%)$ & $0.002^{\star *}$ \\
\hline & Multifocal & $30(40.00 \%)$ & $45(60.00 \%)$ & \\
\hline \multirow[t]{2}{*}{ T stage } & $\mathrm{T} 1-\mathrm{T} 2$ & $38(46.34 \%)$ & $44(53.66 \%)$ & 0.189 \\
\hline & T3-T4 & $17(60.71 \%)$ & $11(39.29 \%)$ & \\
\hline \multirow[t]{2}{*}{ LNM } & N0\&N1a & $34(42.50 \%)$ & $46(57.50 \%)$ & $0.010^{*}$ \\
\hline & N1b & $21(70.00 \%)$ & $9(30.00 \%)$ & \\
\hline \multirow[t]{2}{*}{ 8th AJCC TNM stage } & $I-I I$ & $52(49.50 \%)$ & $53(50.50 \%)$ & 0.647 \\
\hline & IIIIIV & $3(60.00 \%)$ & $2(40.00 \%)$ & \\
\hline \multirow{2}{*}{$\begin{array}{l}2015 \text { ATA Risk Stratification System } \\
\text { Level }\end{array}$} & Low & $14(35.90 \%)$ & $25(64.10 \%)$ & $0.028^{*}$ \\
\hline & $\begin{array}{l}\text { Intermediate \& } \\
\text { High }\end{array}$ & $41(57.75 \%)$ & $30(42.25 \%)$ & \\
\hline \multirow[t]{2}{*}{ BRAF $^{\mathrm{V} 600 \mathrm{E}}$} & Wild type & $26(48.15 \%)$ & $28(51.85 \%)$ & 0.703 \\
\hline & Mutation & $29(51.79 \%)$ & $27(48.21 \%)$ & \\
\hline $\begin{array}{l}\text { Maximum size of tumor (Mean } \pm S D \text {, } \\
\mathrm{cm} \text { ) }\end{array}$ & & $1.73 \pm 0.81$ & $1.41 \pm 0.69$ & $0.018^{*}$ \\
\hline
\end{tabular}

Note: *Statistically significant.

Abbreviations: PRDM16, positive regulatory domain containing 16; PTC: papillary thyroid cancer; FUSCC: Fudan University Shanghai Cancer Center; HT: Hashimoto's thyroiditis; ETE, extrathyroidal extension; 
LNM, lymph node metastasis; TNM: tumor-lymph node-metastasis. 
Table 2

Correlation of PRDM16 expression with clinicopathological characteristics in PTC of the TCGA cohort

\begin{tabular}{|c|c|c|c|c|}
\hline \multicolumn{2}{|l|}{ Variables } & \multirow{2}{*}{$\begin{array}{l}\text { LOW(n = } \\
191) \\
140(49.12 \%)\end{array}$} & \multirow{2}{*}{$\begin{array}{l}\text { HIGH(n = } \\
191) \\
145(50.88 \%)\end{array}$} & \multirow{2}{*}{$\begin{array}{l}P \text {-value } \\
0.557\end{array}$} \\
\hline Gender & Female & & & \\
\hline & Male & $51(52.58 \%)$ & $46(47.42 \%)$ & \\
\hline \multirow{2}{*}{$\begin{array}{l}\text { Age at diagnosis } \\
\text { (years) }\end{array}$} & $<55$ & $124(48.25 \%)$ & $133(51.75 \%)$ & 0.326 \\
\hline & $\geq 55$ & $67(53.6 \%)$ & $58(46.4 \%)$ & \\
\hline \multirow[t]{2}{*}{ ETE } & Yes & 76(73.08\%) & $28(26.92 \%)$ & $\begin{array}{l}< \\
0.001^{\star \star \star}\end{array}$ \\
\hline & No & $103(41.0 \%)$ & 148(59.0\%) & \\
\hline \multirow[t]{3}{*}{$\begin{array}{l}\text { Histological Type } \\
\text { Name }\end{array}$} & Classical & $138(51.30 \%)$ & $131(48.70 \%)$ & $\begin{array}{l}< \\
0.001^{\star \star \star}\end{array}$ \\
\hline & Follicular & $27(32.53 \%)$ & $56(67.47 \%)$ & \\
\hline & $\begin{array}{l}\text { High risk subtypes (Tall } \\
\text { cell,sclerosing, columnar) }\end{array}$ & $26(86.67 \%)$ & $4(13.33 \%)$ & \\
\hline \multirow[t]{2}{*}{ Multifocality } & Unifocal & $159(50.8 \%)$ & $154(49.2 \%)$ & 0.424 \\
\hline & Multifocal & $29(45.31 \%)$ & $35(54.69 \%)$ & \\
\hline \multirow[t]{2}{*}{ T stage } & T1-T2 & $98(40.8 \%)$ & 142(59.2\%) & $\begin{array}{l}< \\
0.001^{\star \star \star}\end{array}$ \\
\hline & T3-T4 & $93(65.49 \%)$ & $49(34.51 \%)$ & \\
\hline \multirow[t]{3}{*}{ LNM } & NO & 73(40.56\%) & $107(59.44 \%)$ & $\begin{array}{l}< \\
0.001^{* * *}\end{array}$ \\
\hline & N1 & $104(64.2 \%)$ & $58(35.8 \%)$ & \\
\hline & $N X$ & 14(37.8\%) & $23(62.2 \%)$ & \\
\hline \multirow[t]{2}{*}{ Metastasis } & MO & $173(48.3 \%)$ & $185(51.7 \%)$ & 0.917 \\
\hline & M1 & $5(50.0 \%)$ & $5(50.0 \%)$ & \\
\hline \multirow[t]{2}{*}{$\begin{array}{l}\text { 8th AJCC TNM } \\
\text { stage }\end{array}$} & $|-| I$ & $111(42.5 \%)$ & $150(57.5 \%)$ & $\begin{array}{l}< \\
0.001^{\star * \star}\end{array}$ \\
\hline & III-IV & $79(65.8 \%)$ & $41(34.2 \%)$ & \\
\hline
\end{tabular}

Note: *Statistically significant. Abbreviations: PRDM16, positive regulatory domain containing 16; PTC: papillary thyroid cancer; TCGA: The Cancer Genomics Atlas; ETE, extrathyroidal extension; LNM, lymph node metastasis; TNM: tumor-lymph node-metastasis. 


\begin{tabular}{|c|c|c|c|c|}
\hline Variables & & $\begin{array}{l}\operatorname{LOW}(n= \\
191)\end{array}$ & $\begin{array}{l}\text { HIGH(n = } \\
191)\end{array}$ & $P$-value \\
\hline \multirow[t]{2}{*}{ BRAF $^{\mathrm{V} 600 \mathrm{E}}$} & Wildtype & $51(32.9 \%)$ & $104(67.1 \%)$ & $\begin{array}{l}< \\
0.001^{* \star \star}\end{array}$ \\
\hline & Mutation & $140(61.67 \%)$ & $87(38.33 \%)$ & \\
\hline
\end{tabular}

A further analysis was performed to estimate whether decreased PRDM16 expression was an independent risk factor for ETE in PTC in both FUSCC and TCGA cohorts. Univariate analysis showed that PRDM16 low expression $(\mathrm{OR}=2.921,95 \% \mathrm{Cl} 1.186-7.192, \mathrm{P}=0.020)$ was a risk factor for ETE in PTC whereas $\mathrm{BRAF}^{\mathrm{V} 600 \mathrm{E}}$ mutation $(\mathrm{OR}=0.4,95 \% \mathrm{Cl} 0.166-0.968, \mathrm{P}=0.042)$ was a protective factor. After adjusting for gender, age, LNM, multifocality, BRAF ${ }^{\mathrm{V} 600 \mathrm{E}}$ mutation and PRDM16 expression level in multivariate analysis, PRDM16 low expression was found to be an independent risk factor remained significant $(\mathrm{OR}=2.914,95 \% \mathrm{Cl} 1.074-7.911, \mathrm{P}=0.036)$. In the TCGA cohort, age $\geq 55$ years, multifocality, LNM, BRAF ${ }^{\mathrm{V} 600 \mathrm{E}}$ mutation and PRDM16 low expression were all demonstrated to be independent risk factors for ETE (Supplementary Table 4 and Supplementary Table 5). Altogether, we supposed that PRDM16 may play a vital role on tumorigenesis of PTC.

\section{Overexpression of PRDM16 suppresses proliferation and migration in PTC cells in vitro}

To investigate whether PRDM16 expression in PTC cell lines recapitulated its expression patterns observed in PTC patient tissues, normal thyroid epithelial cell line Nthy-ori 3 - 1 and three PTC cell lines TPC-1, K1 and BCPAP were tested. PRDM16 was found to be downregulated in TPC-1 $(p<0.001), K 1(p<$ $0.001)$ and BCPAP ( $<0.001)$ cell lines, both transcriptionally (Fig. $2 A)$ and at protein level (Fig. 2B), which was consistent with the data of human PTC tissues, suggesting PRDM16 may be a suppressor gene in PTC. Next, we performed CCK-8 assays and Transwell assays to illuminate the efficacy of PRDM16 on tumor cell proliferation and migration of PTC cell lines. Transcriptional (Fig. 2C) and protein (Fig. 2D) overexpression were successfully achieved after transfection of GV146-PRDM16 plasmids. Cell growth (Fig. 2E) and migration (Fig. 2F) were significantly suppressed in TPC-1, K1 and BCPAP cells overexpressing PRDM16 compared with negative controls.

\section{PRDM16 inhibits epithelial to mesenchymal transition of PTC cell lines}

In the process of tumorigenesis and development, the occurrence of epithelial to mesenchymal transition is an important biological process of tumor cell migration and invasion of epithelial origin. Considering that PRDM16 gene was significantly associated with PTC aggressive behaviors such as lymph node metastasis and primary extra-glandular invasion and PRDM16 overexpression could inhibit the migration ability of PTC cells, we speculated that PRDM16 gene may be involved in the inhibition of EMT in PTC cells. Therefore, we used qRT-PCR to examine EMT-related gene markers mRNA expression in PRDM16- 
overexpressed TPC-1, K1 and BCPAP cells. We found that E-cadherin, the epithelial marker, was significantly increased compared with negative controls. Meanwhile, the mesenchymal markers Ncadherin, Vimentin and MMP3 were significantly decreased compared with negative controls (Fig. 2G). Next, we detected the same change trend of EMT markers in protein levels in three PTC cell lines using western blotting (Fig. 2H). Therefore, we proved that PRDM16 gene participated in the inhibition of EMT in PTC cells.

\section{Overexpression of PRDM16 suppresses PTC tumor growth in vivo}

We then tested anti-tumor effects of PRDM16 in vivo. Firstly, we constructed both BCPAPPRDM16-OE cell line stably over-expressing PRDM16 and BCPAP ${ }^{N C}$ cell line as negative control with $100 \mu \mathrm{g} / \mathrm{ml}$ neomycin during cell culture. The efficiency of transfection was high examined by fluorescence microscope (Supplementary Fig. 2). To observe subcutaneous tumor formation, we injected either BCPAPPRDM16-OE or $B C P A P^{N C}$ into the flanks of nude mice. Each mouse was monitored once every three days and the mice were euthanized after two weeks. As shown in Fig. 2I-J, overexpression of PRDM16 significantly slowed the speed of tumor growth and reduced overall tumor weight in vivo. Immunohistochemistry assay with xenograft tissues showed that PRDM16 overexpression could inhibit Ki-67, a proliferation marker (Fig. 2K). The data further confirmed the anti-tumor activities of PRDM16 in PTC.

\section{PC might participate in the inhibition of EMT process by PRDM16}

To further elucidate the molecular mechanism underlying the anti-tumor effect of PRDM16 in PTC, we performed RNA-sequencing technique to find the downstream target genes of PRDM16 participating in EMT process of PTC cells. Firstly, we overexpressed PRDM16 in K1 and BCPAP cell lines and performed transcriptome sequencing. Figure $3 \mathrm{~A}$ and Fig. 3B showed TOP 30 genes whose expressions were codownregulated or co-upregulated in PRDM16-overexpressing K1 and BCPAP cells. As we found before that PRDM16 gene played a role as a cancer suppressor gene by inhibiting EMT process in PTC, we conducted domestic and foreign literature searches for each gene on List 1 and found out seven genes had been reported to participate in the EMT process. They were RRAD, PTGES, PIM1, LYPD3, PTP4A, PC and RARRES3. Next, we tested these seven genes mRNA expression level in 20 pairs of FUSCC PTC tissue samples and adjacent normal thyroid tissues by qRT-PCR. As shown in Fig. 3C, PC was found to be significantly upregulated in PTC tissues. Meanwhile, we also found PC was upregulated in TPC-1 and K1 cell lines compared with Nthy-ori $3-1$ at both mRNA (Fig. 3D) and protein (Fig. 3E) level, indicating its potential cancer promoting gene role in PTC.

\section{Knockdown of PC suppresses proliferation and migration in PTC cells}

We then evaluated the protumorigenic role of PC in the proliferation and migration of PTC cells. We used siRNAs to knockdown PC mRNA expression level in TPC-1 and K1 and got a significant knockdown efficiency (Fig. 3F). The results showed that both TPC-1(siRNA1, $\mathrm{P}<0.01$; siRNA2, $\mathrm{P}<0.01$ ) and K1 (siRNA1, $\mathrm{P}<0.01$; siRNA2, $\mathrm{P}<0.01$ ) cells transfected with PC-siRNA1 or PC-siRNA2 displayed significantly decreased cell proliferative capacity than that of the siRNA-control vector and blank control (Fig. 3G). As 
shown in Fig. $3 \mathrm{H}$, the migration capacity was examined by Transwell assay and the migrative rate was markedly decreased in the PC-siRNA1 or PC-siRNA2-transfected TPC-1(siRNA1, P<0.001; siRNA2, $\mathrm{P}<$ 0.001 ) and $K 1$ (siRNA1, $P<0.001$; siRNA2, $P<0.001$ ) than in the siRNA-control transfected cells or blank control cells. Thus, we confirmed PC's protumorigenic role in PTC cells.

\section{PRDM16 exhibits anti-tumor effect and EMT inhibition functionon PTC cells via PC}

To confirm whether PRDM16 regulated proliferation and migration and EMT of PTC cells via PC, we determined PC expression level applied qRT-PCR and western blotting in PRDM16-overexpressing TPC-1, $\mathrm{K} 1$ and BCPAP cells. The results showed that PC mRNA level but not protein level was downregulated when PRDM16 was overexpressed in TPC-1, K1 and BCPAP cells (Fig. 4A and Supplementary Fig. 3). Then we performed the rescue experiments by transfecting GV492-PC plasmids into PRDM16overexpressing BCPAP cells and observed the impact on cell proliferation, migration and EMT-related genes changes. In PRDM16-overexpressing BCPAP cells, PC overexpression partially reversed the effect of cell proliferation and migration caused by PRDM16 overexpression (Fig. 4B and Fig. 4C). Meanwhile, PC overexpression could accelerate cell proliferative and migration ability in BCPAP cells (Fig. 4B and Fig. 4C). In addition, PC overexpression significantly reverted the change of EMT-related genes (Ecadherin, N-cadherin, Vimentin and MMP3). We also observed that PC overexpression could decreased Ecadherin protein level and increased N-cadherin, Vimentin and MMP3 protein levels in BCPAP cell line (Fig. 4D), indicating that PC alone could promote EMT process in BCPAP cells. As for xenograft tissues, $\mathrm{IHC}$ assay results (Fig. 4E) showed that PC was expressed significantly lower in BCPAPPRDM16-OE tumor tissues compared with BCPAPPRDM16-NC tumor tissues. Taken together, these data suggested that PRDM16 could suppress tumor progression and EMT process via PC.

\section{PRDM16 Directly Binds To PC Promoter}

Next, we constructed a PC promoter luciferase reporter plasmid and performed a luciferase reporter assay to confirm the mechanistic link between PRDM16 and PC. Firstly, we transfected PC promoter plasmids into PRDM16-overexpressing K1 cells. Compared with the control groups, PRDM16 significantly inhibited PC promoter activity in $\mathrm{K} 1$ cell line (Fig. 4F). To further explore the PRDM16 binding sites within PC promoter, we constructed four 500 bp-length truncated segments of PC promoter luciferase reporter plasmids and repeated the luciferase reporter assay. PC4, the fourth truncated segment of PC promoter, showed significantly inhibited luciferase activity in PRDM16-overexpressing K1 cells (Fig. 4G). Sequences of the fourth truncated segments of PC promoter (PC4) were listed in Supplementary Table 7. To confirm the exact region of PRDM16 binding sites within PC4 truncated segment promoter, we performed chromatin immunoprecipitation (ChIP) in $\mathrm{K} 1$ cell line and found that there was one binding region which existed at approximately from 1500 bp to $1610 \mathrm{bp}$ upstream of the transcription start site (TSS) of PC (Fig. 4H). The abridged diagram of PRDM16 directly binding to PC promoter was illustrated in Fig. 4I. 
To determine the clinical significance of PC in PTC, we assessed PC mRNA expression in 60 pairs of PTC tissue samples and their adjacent normal thyroid tissues from FUSCC. The results revealed that PC was upregulated in PTC samples compared with adjacent normal thyroid tissues ( $P<0.001$, Fig. 5A). 50 of 60 PTC patients (83.33\%) presented higher PC expression level in tumor tissue than that in paired normal tissue, while only $16.67 \%$ patients had lower PC expression level (Fig. 5B). The correlation of PC with the clinicopathological characteristics of 382 PTC patients from TCGA cohort were analyzed, as shown in Supplementary Table 6. The results of TCGA cohort showed that high PC expression was significantly related with $\operatorname{LNM}(P=0.001)$, ETE $(P<0.001)$ and BRAF ${ }^{\mathrm{V} 600 \mathrm{E}}$ mutation $(P<0.001)$.

IHC analysis $(\mathrm{P}<0.01$, Fig. $5 \mathrm{C})$ confirmed high $\mathrm{PC}$ protein expression in $\mathrm{PTC}$ and low $\mathrm{PC}$ protein expression in normal thyroid tissue specimens. Moreover, consistent with our previous data in vitro, the expression level of PC in PTC patients with low PRDM16 expression were significantly higher than that in patients with high PRDM16 expression $(P<0.05$, Fig. 5D). Furthermore, we probed into the relationship between PRDM16 mRNA expression and PC mRNA expression using linear regression in both FUSCC and TCGA cohorts. Figure 5E-F indicated that PC mRNA expression was significantly negative-related with PRDM16 mRNA expression level in PTC patients from both FUSCC $(R=-0.2876, P<0.05)$ and TCGA $(R=-0.31, P<0.001)$ cohorts. Therefore, we finally demonstrated $P C$ was downregulated by PRDM16 in PTC tissues.

\section{Discussion}

Papillary thyroid cancer comprises the majority of all thyroid cancers and has a promising well prognosis. Traditional treatment for PTC includes total or subtotal thyroidectomy, radioactive iodine and thyroid hormone inhibitory therapy. However, advanced, progressive and radioactive iodine (RAI) refractory differentiated thyroid cancers could be lethal due to limited effective treatment options. In this study, we illustrated the regulatory function of PRDM16 in the regulation of papillary thyroid carcinogenesis. Here, we identified PRDM16 exhibited antitumor activities toward cancer cell proliferation and migration by its targeting of pyruvate carboxylase and regulating epithelia-to-mesenchymal transition. This preclinical study is the first time to illustrate the involvement of PRDM16 as a potential tumor suppressor gene in PTC and explain the underlying mechanism of its regulatory role on PTC.

The presence of extrathyroidal extension and lymph node metastases are regarded as important factors affecting recurrence and survival of PTC. Jason B. Clain, et al showed that patients with minimal ETE were significantly more likely to have extranodal extension in positive lymph nodes (28), manifesting its aggressive behavior. It is imperative for surgeons and patients to know the possibility of ETE before surgery, in order to decide the extent of the surgery (29). Besides, ETE is also the critical determinants for postoperative radioactive iodine treatment. Our study showed that PTC patients with ETE had a significantly higher percentage in PRDM16 low expression level compared with that in high expression level, in both the FUSCC and TCGA cohorts. Meanwhile, PRDM16 low expression was demonstrated as an independent risk factor for ETE of PTC in the FUSCC cohort which was also validated in TCGA cohort. Central lymph node dissection now is a widely accepted procedure and currently performed routinely in 
the treatment of thyroid cancer in many institutions. Although The 2015 ATA guidelines state that data to determine risk based on LN metastases' location are insufficient, recent studies confirmed that the persistent/ recurrence disease and distant metastases were significantly more frequent in patients with lateral-cervical LN (N1b) metastases (30). Our study demonstrated that low PRDM16 level was significantly related with N1b status in both the FUSCC and TCGA cohorts. In conclusion, we identified that PTC patients with low PRDM16 expression level were more likely to have ETE and N1b presence. Therefore, PRDM16 could serve as a biomarker for aggressive behavior of PTC.

PRDM16 is a member of PR domain zinc finger family. It was first discovered and deeply studied in AML and MLL. It could suppress mixed lineage leukemia through its intrinsic histone methyltransferase activity of the PR domain. In 2008, Seale et al. reported that it plays a decisive role as a transcription factor in the conversion of white adipocytes to brown adipocytes and is a co-activator of PPARY15 (16). Therefore, PRDM16 can play a role in transcription factor regulation. Apart from the study in hematologic neoplasm, recent researches have explored controversial functions of PRDM16 gene in solid cancers, such as gastric cancer, prostate cancer, esophageal squamous cell cancer and lung cancer. Our results determined PRDM16 as a tumor suppressor gene in papillary thyroid cancer and found loss of PRDM16 was prevalent in PTC tissues.

Our study discovered that PRDM16 interacted directly with the pyruvate carboxylase (PC) promoter and regulated the expression of PC transcriptionally. PC is an enzyme that exists in human mitochondria. It is a rate-limiting enzyme that catalyzes the decarboxylation of pyruvate to form acetyl-CoA. In recent years, the role of PC in tumor cells has been gradually reported (31). Stefan Christen et al. (32) found that the process of lung metastasis in breast cancer relies on the glucose metabolism pathway that PC participates in. The increased PC expression promotes lung metastasis in breast cancer. In addition, PC can also promote the proliferation of non-small cell lung cancer cells (33) and malignant glioma cells (34). As for thyroid cancer, a latest study has reported that increased expression of PC in papillary thyroid cancer could reprogram energy metabolism (35). Our research not only confirmed the upregulated expression of PC both in PTC tissues and PTC cell lines, we also found significant relationship between $\mathrm{PC}$ high expression with lymph node metastasis, extrathyroidal extension and BRAF ${ }^{\mathrm{V} 600 \mathrm{E}}$ mutation in PTC from TCGA database, indicating its role as a tumor promoting gene in PTC. Knockdown of PC could attenuate PTC cell proliferation and migration, which was consistent with previous study. Our results firstly reported that PRDM16 directly bound to the promoter region of PC and inhibited its expression, reinforcing the importance of PC in PRDM16 mediated tumorigenesis. Furthermore, increased PC expression in PTC cells reversed the inhibition of cell proliferation and migration induced by PRDM16.

The occurrence of epithelial to mesenchymal transition is an important biological process of tumor cell migration and invasion (36). By losing the characteristics of epithelial cells, tumor cells acquire the characteristics of mesenchymal cells, which can migrate and invade, making tumors more likely to invade surrounding tissues or metastasize. Therefore, exploring the molecular mechanism of EMT process in tumor development and finding molecular targets of EMT pathways is of great significance for predicting and treating tumor invasion and metastasis. The role of EMT in the development of papillary 
thyroid cancer has been proven $(37,38)$. We used RNA-sequencing technique and found seven genes which have been reported to be related with EMT process. They were RRAD (39), PTGES (40), PIM1 (41), LYPD3 (42), PTP4A (43), RARRES3 $(44,45)$ and PC. In 2012, Sun Yeon Lee et al. (46) reported a study on the relationship between PC and EMT in breast tumor cell line MCF-7. They found that PC can affect mitochondrial respiratory process through the Wnt/Snail pathway and thus regulates EMT process. Unfortunately, the research team failed to prove direct binding of Wnt/Snail to the PC promoter region, but they confirmed that PC can take part in the EMT process. Our research suggested that PC could promote EMT process in papillary thyroid cancer. Meanwhile, our qRT-PCR results showed a significant suppression of PC mRNA expression by PRDM16 but Western blot did not show a significant downregulation of PC protein expression. Therefore, we focused on how PRDM16 downregulates PC expression at transcriptional level. Luciferase assay and ChIP assay indicated that PRDM16 exhibited anti-tumor activities in PTC as a transcription factor through binding to PC promoter, thus inhibiting PC promoter activity at transcriptional level and further suppressing EMT process of PTC tumor cells. The mechanism of whether PRDM16 affects PC at translational level remains unclear. Therefore, PRDM16 and PC, as key molecules involved in EMT pathway of PTC cells, may be involved in the migration behavior of PTC, including extra-glandular invasion of tumors, lymph node metastasis and even distant metastasis. PRDM16 and PC can be used as molecular targets for future EMT therapy on papillary thyroid cancer.

The main limitations of this study are the small sample size of the FUSCC cohort and the retrospective nature of the data analysis. Firstly, small sample size and the selection bias in the FUSCC cohort led to inconsistent results compared with that in the TCGA cohort. We demonstrated low PRDM16 expression level was significantly associated with histological type and BRAF ${ }^{\mathrm{V} 600 \mathrm{E}}$ mutation in the TCGA cohort. As for the histological type, the tall-cell and sclerosing type of PTC, which were aggressive histologies, had a higher proportion in the PRDM16 low level group. However, the FUSCC cohort had no patients with a tallcell or a sclerosing histological type of PTC, therefore it was impossible to assess its relationship with PRDM16. In the FUSCC cohort we found out that the percentage of patients harboring BRAF ${ }^{\mathrm{V} 600 \mathrm{E}}$ mutation in the PRDM16low expression group (51.79\%) was higher than that in high expression group (48.21\%), but it failed to show significance. Meanwhile, small sample size and maldistribution of clinical data led to an opposite result of BRAF ${ }^{\mathrm{V} 600 \mathrm{E}}$ in ETE risk factors multivariable analysis between our FUSCC cohort and TCGA cohort. Therefore, more patients should be enrolled in the study to enlarge the sample size to further explore the significant correlated clinicalpathological factors with PRDM16 and the predictive factors for extrathyroidal extension. Secondly, all of the studied patients should have long term follow-up to see if PRDM16 could affect the prognosis of PTC. Moreover, further studies are needed to explore the underlying molecular mechanisms of PRDM16 function in PTC.

\section{Conclusions}

In summary, our study demonstrated that PRDM16 is downregulated in PTC tissues and PTC cell lines TPC-1, K1 and BCPAP. Meanwhile, the relationship between PRDM16 low expression and lymph node 
metastasis and extrathyroidal extension of papillary thyroid cancer patients from TCGA was in line with our FUSCC data, indicating that PRDM16 can be a novel marker for the prognosis of PTC patients. In vitro and in vivo data showed that overexpression of PRDM16 attenuated cell proliferation and migration of PTC cells, confirming the vital function of PRDM16 in PTC. Further mechanism study demonstrated that the role of PRDM16 in PTC may result from the regulation of EMT via its directly binding to pyruvate carboxylase promoter. Thus, PRDM16 may present as a new biomarker of favorable prognosis in papillary thyroid cancer and as a potential novel target for the treatment of papillary thyroid cancer.

\section{List Of Abbreviations}

ChIP chromatin immunoprecipitation;

$\mathrm{Cl}$ confidence interval

EMT epithelial to mesenchymal transition

ETE extrathyroidal extension

FUSCC Fudan university Shanghai cancer center

GAPDH glyceraldehyde-3-phosphate dehydrogenase

HT Hashimoto's thyroiditis

IHC immunohistochemistry

LNM lymph node metastasis

MMP3 matrix metalloproteinase 3

NC negative control

OE over expression

OR odd ratio

PC pyruvate carboxylase

PPARy peroxisome proliferator-activated receptor gamma

PRDM16 positive regulatory domain-containing 16

PTC papillary thyroid cancer

qRT-PCR quantitative real-time polymerase chain reaction 
ROC receiver operation curve

TCGA the Cancer Genome Atlas

TGF- $\beta$ transforming growth factor- $\beta$

TSS transcription start site

TNM tumor lymph node and metastasis.

\section{Declarations}

\section{Ethics approval and consent to participate}

This study was performed in accordance with the 1964 Helsinki Declaration and its later amendments or comparable ethical standards. It was approved by the Human Ethics Committee/Institutional Review Board of Fudan University Shanghai Cancer Center. Animal experiments have been preapproved by the Animal Experimentation Ethics committee of Fudan University Shanghai Cancer Center. All procedures were performed in accordance with the National Institutes of Health Guide for the Care and Use of Laboratory Animals.

\section{Consent for publication}

Not applicable.

\section{Availability of data and materials}

The datasets supporting the conclusions of this article are included within the article and its additional files.

\section{Competing interests}

The authors declare that they have no competing interests.

\section{Funding}

This work was supported by the National Natural Science Foundation of China (81772854,81572622 to Qing-Hai JI, 81702753 to Tian LIAO), the Science and Technology Commission of Shanghai Municipality 19411966600 (to Yu Wang) and Shanghai municipal planning commission of science and research fund for young scholar (20154Y0050 to Jun Xiang).

\section{Authors' contributions}


WLL performed cell line culture, Luciferase assay, ChIP assay, statistical analysis, and wrote the paper; QG performed FUSCC human tissues collection and helped write the paper; WD performed cell proliferation and migration, and Western blot; BM helped mechanism exploration and statistical analysis; WBX finished the xenograft assays; JQH did the qRT-PCR; WWJ finished IHC assay; DSL and YW provided human PTC tissues; JX and TL provided technical support and tissue clinical data; QHJ designed this project and supervised this project. All authors read and approved the final manuscript.

\section{Acknowledgements}

Not applicable.

\section{References}

1. Chen AY, Jemal A, Ward EM. Increasing incidence of differentiated thyroid cancer in the United States, 1988-2005. Cancer. 2009;115(16):3801-7.

2. Bray F, Ferlay J, Soerjomataram I, Siegel RL, Torre LA, Jemal A. Global cancer statistics 2018: GLOBOCAN estimates of incidence and mortality worldwide for 36 cancers in 185 countries. CA Cancer J Clin. 2018;68(6):394-424.

3. Cancer Genome Atlas Research N. Integrated genomic characterization of papillary thyroid carcinoma. Cell. 2014;159(3):676-90.

4. Kitahara CM, Sosa JA. The changing incidence of thyroid cancer. Nat Rev Endocrinol. 2016;12(11):646-53.

5. Hay ID, Thompson GB, Grant CS, Bergstralh EJ, Dvorak CE, Gorman CA, et al. Papillary thyroid carcinoma managed at the Mayo Clinic during six decades (1940-1999): temporal trends in initial therapy and long-term outcome in 2444 consecutively treated patients. World J Surg. 2002;26(8):879-85.

6. Leboulleux S, Rubino C, Baudin E, Caillou B, Hartl DM, Bidart JM, et al. Prognostic factors for persistent or recurrent disease of papillary thyroid carcinoma with neck lymph node metastases and/or tumor extension beyond the thyroid capsule at initial diagnosis. J Clin Endocrinol Metab. 2005;90(10):5723-9.

7. Carling T, Udelsman R. Thyroid cancer. Annu Rev Med. 2014;65:125-37.

8. Mazzaferri EL, Massoll N. Management of papillary and follicular (differentiated) thyroid cancer: new paradigms using recombinant human thyrotropin. Endocr Relat Cancer. 2002;9(4):227-47.

9. Caronia LM, Phay JE, Shah MH. Role of BRAF in thyroid oncogenesis. Clin Cancer Res. 2011;17(24):7511-7.

10. Xing M, Alzahrani AS, Carson KA, Shong YK, Kim TY, Viola D, et al. Association between BRAF V600E mutation and recurrence of papillary thyroid cancer. J Clin Oncol. 2015;33(1):42-50. 
11. Liu X, Qu S, Liu R, Sheng C, Shi X, Zhu G, et al. TERT promoter mutations and their association with BRAF V600E mutation and aggressive clinicopathological characteristics of thyroid cancer. J Clin Endocrinol Metab. 2014;99(6):E1130-6.

12. Cabanillas ME, Patel A, Danysh BP, Dadu R, Kopetz S, Falchook G. BRAF inhibitors: experience in thyroid cancer and general review of toxicity. Horm Cancer. 2015;6(1):21-36.

13. Falchook GS, Millward M, Hong D, Naing A, Piha-Paul S, Waguespack SG, et al. BRAF inhibitor dabrafenib in patients with metastatic BRAF-mutant thyroid cancer. Thyroid. 2015;25(1):71-7.

14. Fumasoni I, Meani N, Rambaldi D, Scafetta G, Alcalay M, Ciccarelli FD. Family expansion and gene rearrangements contributed to the functional specialization of PRDM genes in vertebrates. BMC Evol Biol. 2007;7:187.

15. Mochizuki N, Shimizu S, Nagasawa T, Tanaka H, Taniwaki M, Yokota J, et al. A novel gene, MEL1, mapped to $1 p 36.3$ is highly homologous to the MDS1/EVI1 gene and is transcriptionally activated in $\mathrm{t}(1 ; 3)$ (p36;q21)-positive leukemia cells. Blood. 2000;96(9):3209-14.

16. Seale P, Bjork B, Yang W, Kajimura S, Chin S, Kuang S, et al. PRDM16 controls a brown fat/skeletal muscle switch. Nature. 2008;454(7207):961-7.

17. Seale P, Conroe HM, Estall J, Kajimura S, Frontini A, Ishibashi J, et al. Prdm16 determines the thermogenic program of subcutaneous white adipose tissue in mice. J Clin Invest. 2011;121(1):96105.

18. Seale P, Kajimura S, Yang W, Chin S, Rohas LM, Uldry M, et al. Transcriptional control of brown fat determination by PRDM16. Cell Metab. 2007;6(1):38-54.

19. Jo A, Mitani S, Shiba N, Hayashi Y, Hara Y, Takahashi H, et al. High expression of EVI1 and MEL1 is a compelling poor prognostic marker of pediatric AML. Leukemia. 2015;29(5):1076-83.

20. Shiba N, Ohki K, Kobayashi T, Hara Y, Yamato G, Tanoshima R, et al. High PRDM16 expression identifies a prognostic subgroup of pediatric acute myeloid leukaemia correlated to FLT3-ITD, KMT2A-PTD, and NUP98-NSD1: the results of the Japanese Paediatric Leukaemia/Lymphoma Study Group AML-05 trial. Br J Haematol. 2016;172(4):581-91.

21. Zhou B, Wang J, Lee SY, Xiong J, Bhanu N, Guo Q, et al. PRDM16 Suppresses MLL1r Leukemia via Intrinsic Histone Methyltransferase Activity. Mol Cell. 2016;62(2):222-36.

22. Takahata M, Inoue $Y$, Tsuda H, Imoto I, Koinuma D, Hayashi M, et al. SKI and MEL1 Cooperate to Inhibit Transforming Growth Factor- $\beta$ Signal in Gastric Cancer Cells. J Biol Chem. 2009;284(5):333444.

23. Zhu S, Xu Y, Song M, Chen G, Wang H, Zhao Y, et al. PRDM16 is associated with evasion of apoptosis by prostatic cancer cells according to RNA interference screening. Mol Med Rep. 2016;14(4):335761.

24. Peng X, Xue H, Lu L, Shi P, Wang J, Wang J. Accumulated promoter methylation as a potential biomarker for esophageal cancer. Oncotarget. 2017;8(1):679-91.

25. Tan S, Hu R, Liu J, Tan Y, Liu W. Methylation of PRDM2, PRDM5 and PRDM16 genes in lung cancer cells. Int J Clin Exp Pathol. 2014;7(5):2305-11. 
26. Zhang M, Wu J, Mao K, Deng H, Yang Y, Zhou E, et al. Role of transforming growth factor-beta1 in triple negative breast cancer patients. Int J Surg. 2017;45:72-6.

27. Haugen BR, Alexander EK, Bible KC, Doherty GM, Mandel SJ, Nikiforov YE, et al. 2015 American Thyroid Association Management Guidelines for Adult Patients with Thyroid Nodules and Differentiated Thyroid Cancer: The American Thyroid Association Guidelines Task Force on Thyroid Nodules and Differentiated Thyroid Cancer. Thyroid. 2016;26(1):1-133.

28. Clain JB, Scherl S, Dos Reis L, Turk A, Wenig BM, Mehra S, et al. Extrathyroidal Extension Predicts Extranodal Extension in Patients with Positive Lymph Nodes: An Important Association That May Affect Clinical Management. Thyroid. 2014;24(6):951-7.

29. Lee DY, Kwon TK, Sung MW, Kim KH, Hah JH. Prediction of extrathyroidal extension using ultrasonography and computed tomography. Int J Endocrinol. 2014;2014:351058.

30. Sapuppo G, Palermo F, Russo M, Tavarelli M, Masucci R, Squatrito S, et al. Latero-cervical lymph node metastases $(\mathrm{N} 1 \mathrm{~b})$ represent an additional risk factor for papillary thyroid cancer outcome. $J$ Endocrinol Invest. 2017;40(12):1355-63.

31. Shinde A, Wilmanski T, Chen H, Teegarden D, Wendt MK. Pyruvate carboxylase supports the pulmonary tropism of metastatic breast cancer. Breast Cancer Res. 2018;20(1):76.

32. Christen S, Lorendeau D, Schmieder R, Broekaert D, Metzger K, Veys K, et al. Breast Cancer-Derived Lung Metastases Show Increased Pyruvate Carboxylase-Dependent Anaplerosis. Cell Rep. 2016;17(3):837-48.

33. Sellers K, Fox MP, Bousamra M 2nd, Slone SP, Higashi RM, Miller DM, et al. Pyruvate carboxylase is critical for non-small-cell lung cancer proliferation. J Clin Invest. 2015;125(2):687-98.

34. Cheng T, Sudderth J, Yang C, Mullen AR, Jin ES, Mates JM, et al. Pyruvate carboxylase is required for glutamine-independent growth of tumor cells. Proc Natl Acad Sci U S A. 2011;108(21):8674-9.

35. Strickaert A, Corbet C, Spinette SA, Craciun L, Dom G, Andry G, et al. Reprogramming of Energy Metabolism: Increased Expression and Roles of Pyruvate Carboxylase in Papillary Thyroid Cancer. Thyroid. 2019;29(6):845-57.

36. Lamouille S, Xu J, Derynck R. Molecular mechanisms of epithelial-mesenchymal transition. Nat Rev Mol Cell Biol. 2014;15(3):178-96.

37. Baquero P, Sanchez-Hernandez I, Jimenez-Mora E, Orgaz JL, Jimenez B, Chiloeches A. (V600E)BRAF promotes invasiveness of thyroid cancer cells by decreasing E-cadherin expression through a Snaildependent mechanism. Cancer Lett. 2013;335(1):232-41.

38. Knauf JA, Sartor MA, Medvedovic M, Lundsmith E, Ryder M, Salzano M, et al. Progression of BRAFinduced thyroid cancer is associated with epithelial-mesenchymal transition requiring concomitant MAP kinase and TGFbeta signaling. Oncogene. 2011;30(28):3153-62.

39. Yeom SY, Nam DH, Park C. RRAD promotes EGFR-mediated STAT3 activation and induces temozolomide resistance of malignant glioblastoma. Mol Cancer Ther. 2014;13(12):3049-61.

40. Wang $T$, Jing $B, X u D$, Liao Y, Song H, Sun B, et al. PTGES/PGE2 signaling links immunosuppression and lung metastasis in Gprc5a-knockout mouse model. Oncogene. 2020. 
41. Zhao B, Liu L, Mao J, Zhang Z, Wang Q, Li Q. PIM1 mediates epithelial-mesenchymal transition by targeting Smads and c-Myc in the nucleus and potentiates clear-cell renal-cell carcinoma oncogenesis. Cell Death Dis. 2018;9(3):307.

42. Oshiro R, Yamamoto H, Takahashi H, Ohtsuka M, Wu X, Nishimura J, et al. C4.4A is associated with tumor budding and epithelial-mesenchymal transition of colorectal cancer. Cancer Sci. 2012;103(6):1155-64.

43. Wang H, Quah SY, Dong JM, Manser E, Tang JP, Zeng Q. PRL-3 down-regulates PTEN expression and signals through PI3K to promote epithelial-mesenchymal transition. Cancer Res. 2007;67(7):2922-6.

44. Hsu TH, Jiang SY, Chang WL, Eckert RL, Scharadin TM, Chang TC. Involvement of RARRES3 in the regulation of Wnt proteins acylation and signaling activities in human breast cancer cells. Cell Death Differ. 2015;22(9):1561.

45. Morales M, Arenas EJ, Urosevic J, Guiu M, Fernandez E, Planet E, et al. RARRES3 suppresses breast cancer lung metastasis by regulating adhesion and differentiation. EMBO Mol Med. 2014;6(7):86581.

46. Lee SY, Jeon HM, Ju MK, Kim CH, Yoon G, Han SI, et al. Wnt/Snail signaling regulates cytochrome $\mathrm{C}$ oxidase and glucose metabolism. Cancer Res. 2012;72(14):3607-17.

\section{Figures}


A

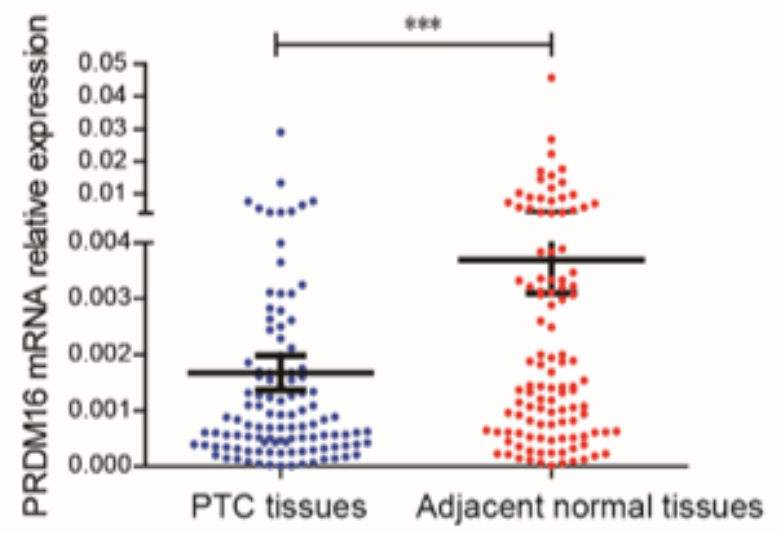

\section{C}

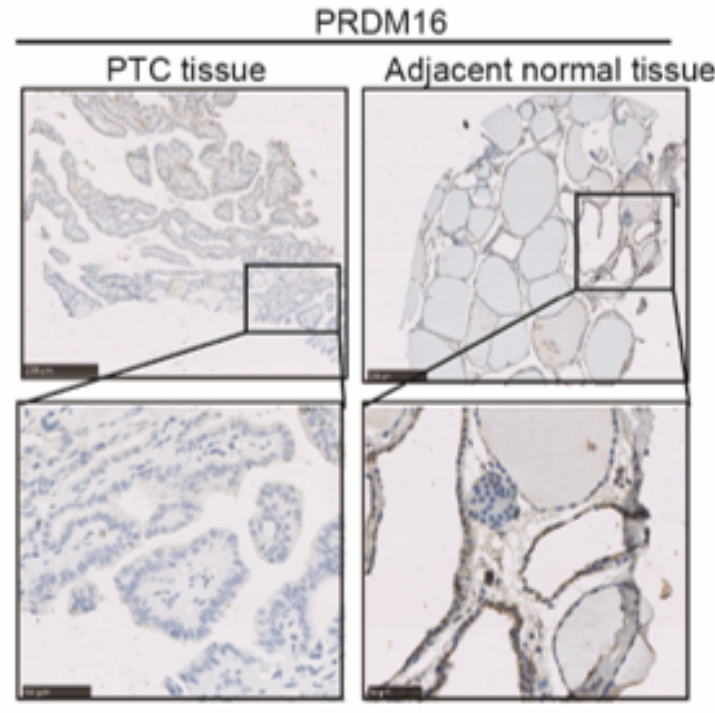

B

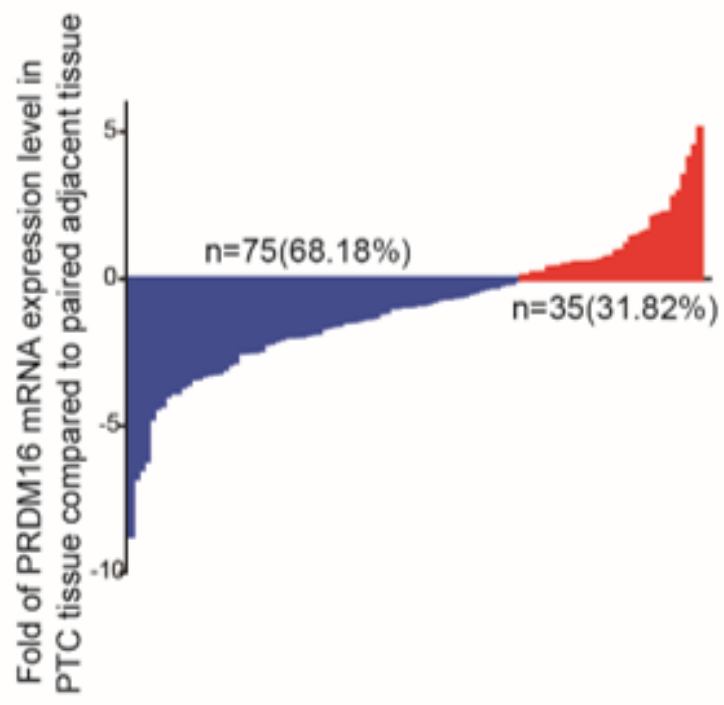

\section{Figure 1}

PRDM16 expression was downregulated in human PTC tissues. (A) PRDM16 mRNA expression level between tumor and normal tissues in 110 PTC patients from FUSCC. The results were normalized to $\beta-$ actin mRNA level. (B) Waterfall plot showed the distribution of PRDM16 expression level in each PTC patients from FUSCC. (C) IHC staining of PRDM16 expression in formalin-fixed, paraffin-embedded PTC and corresponding non-tumor thyroid tissues (original magnification, x100, x400). PRDM16 was expressed strongly negative in PTC tissues and almost positive in normal thyroid regions. ${ }^{*} * \mathrm{P}<0.001$, ${ }^{*} \mathrm{P}<0.05$, data were pooled from three independent experiments. Abbreviations: FUSCC: Fudan University Shanghai Cancer Center; IHC, immunohistochemistry; PRDM16, positive regulatory domain containing 16; PTC, papillary thyroid cancer. 

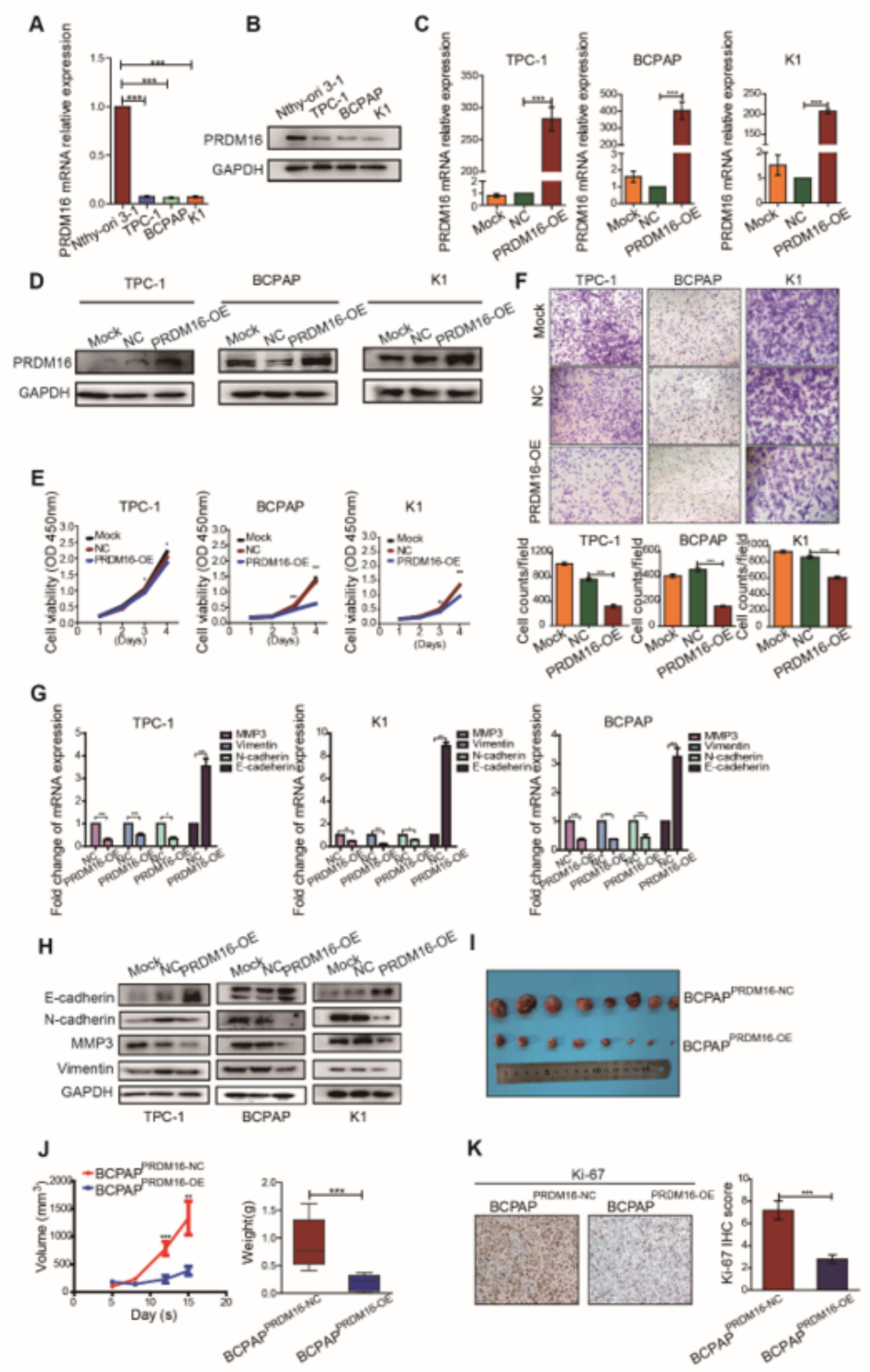

\section{Figure 2}

PRDM16 inhibited PTC cell proliferation, migration and epithelial-mesenchymal transition in vitro and tumorigenicity in vivo. (A) PRDM16 mRNA expression level in one normal thyroid cell line Nthy-ori-3-1 and three PTC cell lines, TPC-1, BCPAP and K1. The results were normalized to $\beta$-actin mRNA level. The relative quantification of PRDM16 expression in PTC cell lines was measured as fold to Nthy-ori-3-1 cell line. (B) Western blotting confirmed PRDM16 protein expression level in Nthy-ori-3-1, TPC-1, BCPAP and 
K1 cell lines. ( $C$ and D) Overexpression efficiency of PRDM16 in TPC-1, BCPAP and K1 cell lines confirmed by qRT-PCR and Western blot analysis. (E) PRDM16 overexpression significantly inhibited cell proliferative ability of TPC-1, BCPAP and K1 examined by CCK-8 assay. (F) Overexpressed PRDM16 significantly inhibited cell migration ability of TPC-1, BCPAP and K1 examined by Transwell assay. (G) PRDM16 overexpression significantly downregulated mesenchymal markers, MMP3, N-cadherin and Vimentin mRNA expression levels. E-cadherin, the epithelial marker, was significantly upregulated by PRDM16 overexpression in mRNA level. The results were normalized to $\beta$-actin mRNA level. (H) PRDM16 overexpression downregulated MMP3, N-cadherin and Vimentin protein levels and upregulated E-cadherin protein level by Western blotting assay. The results were normalized to GAPDH protein level. (I and $\mathrm{J}$ ) Tumor volume and weight of recipient mice transfected with BCPAPPRDM16-OE and BCPAPPRDM16-NC cell lines. (K) IHC staining of Ki-67 expression in formalin-fixed, paraffin-embedded recipient mice PTC tissues of BCPAPPRDM16-OE and BCPAPPRDM16-NC (original magnification, $\mathrm{x} 100, \mathrm{x} 400$ ). Ki-67 was expressed significantly negative in BCPAPPRDM16-OE PTC tissues. ${ }^{*} P<0.05,{ }^{*} P<0.01,{ }^{*} * * P<0.001$, data were pooled from three independent experiments. Abbreviations: IHC: immunohistochemistry; PRDM16: positive regulatory domain containing 16; PTC: papillary thyroid cancer. 
A

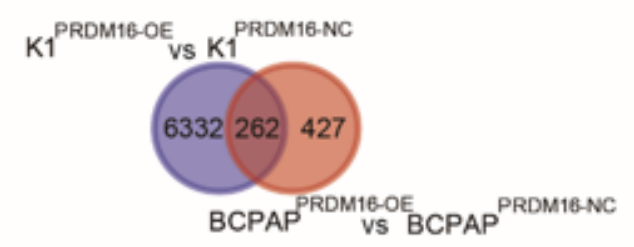

B

$K 1^{\text {PRDM16-OE }}$ VS $K 1^{\text {PRDM16-NC }}$

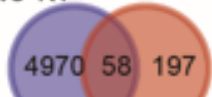

C

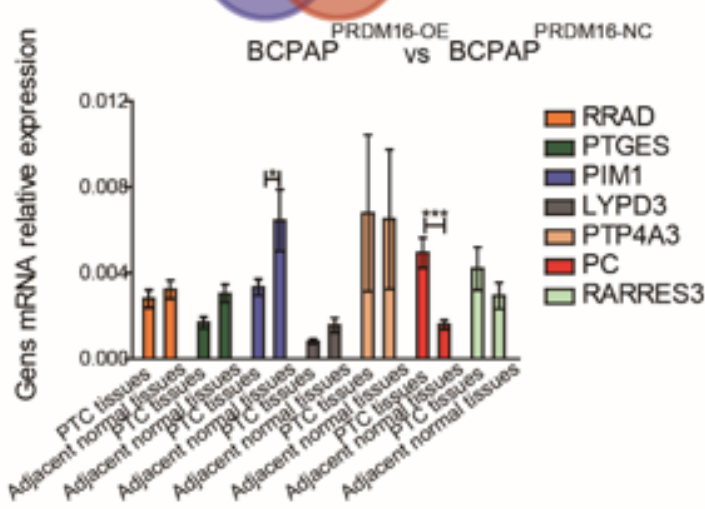

D

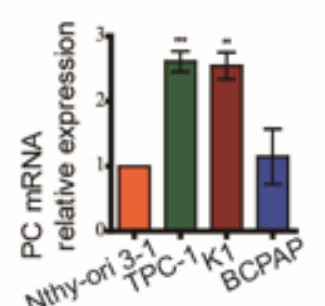

E

G

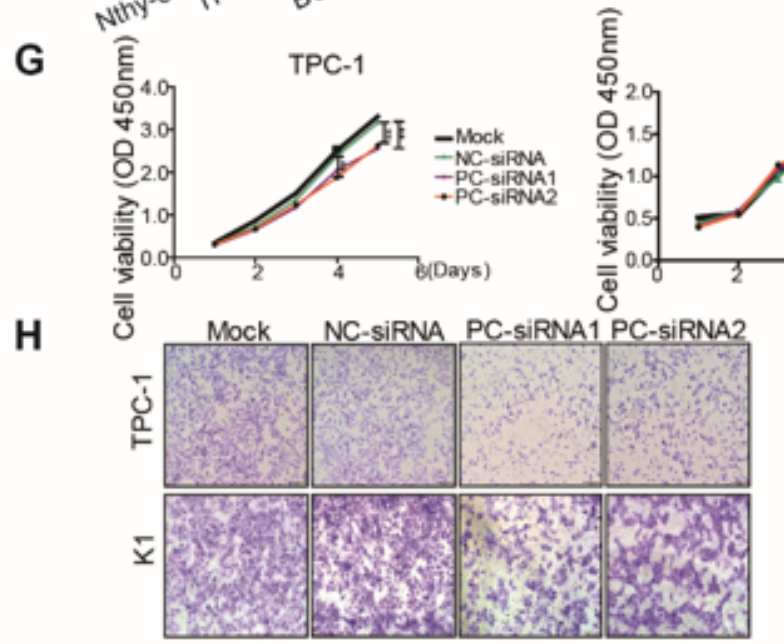

H

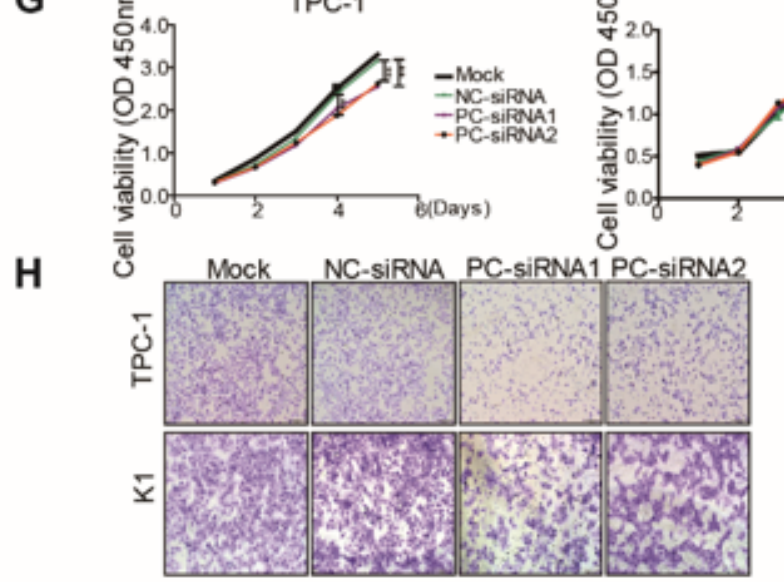

List 1 Top 30 genes

downregulated by PRDM16

GenelDFC_K1 FC_BCPAP

CDKN1C $0.054 \quad 0.615$

$\begin{array}{lll}\text { GPRC5C } & 0.186 & 0.787\end{array}$

$\begin{array}{lll}\text { RRAD } & 0.189 & 0.782\end{array}$

$\begin{array}{lll}\text { FPR1 } & 0.205 & 0.648\end{array}$

$\begin{array}{lll}\text { GPR84 } & 0.219 & 0.682\end{array}$

$\begin{array}{lll}\text { UTAF } & 0.267 & 0.781 \\ \text { HTRA1 } & 0.268 & 0.466\end{array}$

$\begin{array}{ll}\text { HTRA1 } & 0.268 \\ \text { CEBPD } & 0.290\end{array}$

FKBP1B 0.29

$\begin{array}{ll}\text { TM7SF2 } & 0.38 \\ \text { ALDH31 } & 0.393\end{array}$

$P M$

NTNG2 0.413

SECTM1 0.423

BDKRB1 0.437

PY

PTP4A3 3.44

HIST1H3E 0.44

DES 0.452

$\begin{array}{ll}\text { DES } & 0.452 \\ \text { PC } & 0.465\end{array}$

$\begin{array}{lll}\text { VGF } & 0.466 \\ \text { C17orf103 } & 0.469\end{array}$

SLC22A 180.479

RARRES3 0.501

ADA 0.515

0.68

0.705

0.635

0.749

0.747

0.734
0.777

0.730

0.692

0.610
0.798
0.551

0.551

0.713
0.786

0.750

0.718

0.726
List 2 Top 30 genes

upregulated by PRDM16

GenelDFC K1 FC_BCPAP

PRDM16 99.009 13.158

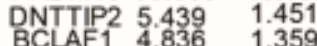

$\begin{array}{lll}\text { MBNL1 } & 4.745 & 1.369\end{array}$

DEK $4.677 \quad 1.501$

$\begin{array}{lll}\text { TWF1 } & 4.594 & 1.599 \\ \text { THOC1 } & 3.900 & 1.519\end{array}$

$\begin{array}{lll}\mathrm{TH} 1 & 3.862 & 1.546\end{array}$

$\begin{array}{lll}\text { RIOK1 } & 3.732 & 1.333 \\ \text { MME } & 3.713 & 1.312\end{array}$

CENPK $3.708 \quad 1.495$

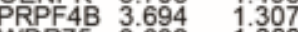

WDR75 3.6821 .388

$\begin{array}{lll}\text { ANXA1 } & 3.634 & 1.759 \\ \text { CD46 } & 3.614 & 1.692\end{array}$

ABCB10 $3.559 \quad 1.369$

EIF1AX $3.482 \quad 1.433$

SMEK2 $3.406 \quad 1318$

PPP1CB $3.394 \quad 1.439$

$\mathrm{PLOD} 2330$

CDK1 3.315 1.363

NAA 2 3. $399 \quad 1.399$

1.341

$\begin{array}{lll}\text { CTNNAL1 } & 3.237 & 1.403 \\ \text { NAB1 } & 3.230 & 1.371\end{array}$

$\begin{array}{lll}\text { NAB1 } & 3.230 & 1.371 \\ \text { OSBPL8 } & 3.221 & 1.317\end{array}$

\begin{tabular}{lll} 
ZBED5 & 3.214 & 1.449 \\
EXO1 & 3.198 & 1.343 \\
\hline
\end{tabular}

F
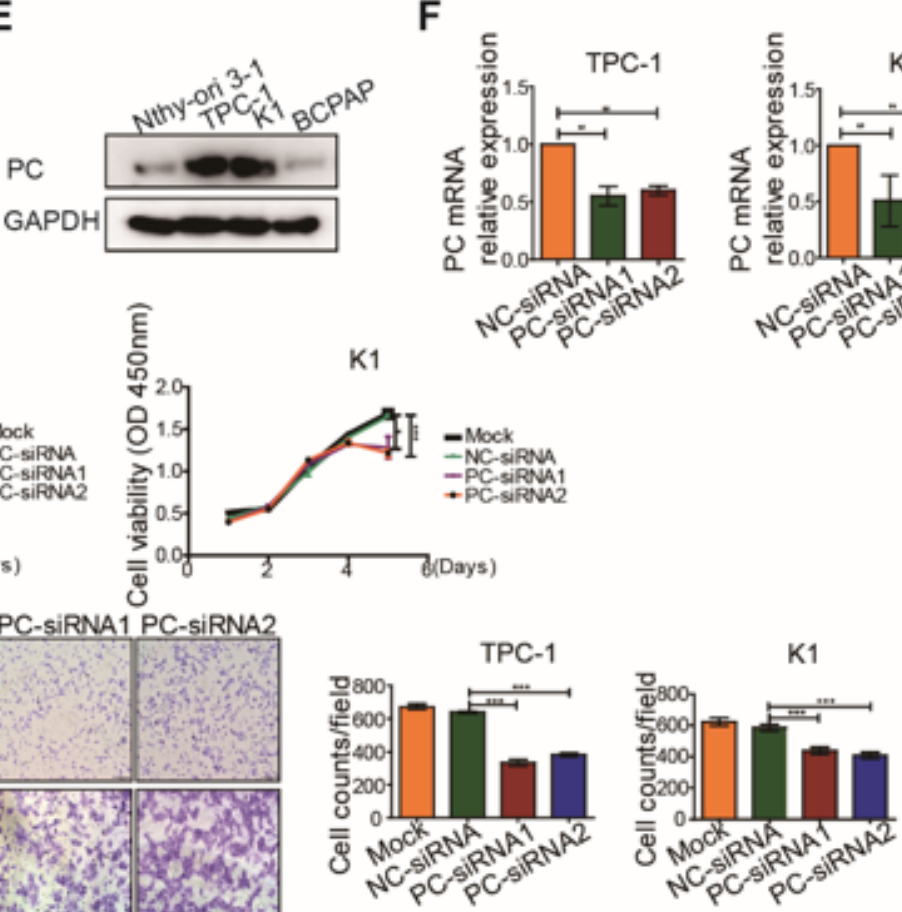

Figure 3

PC was downregulated by PRDM16 and showed a reverse phenocopy of PRDM16 in PTC cells. (A) Venn diagram showed genes downregulated by PRDM16 overexpression in both K1 and BCPAP cell lines by RNA-sequencing. The top 30 co-downregulated genes were listed in List 1. PC was significantly downregulated in both $\mathrm{K} 1$ and BCPAP cell lines. (B) Venn diagram showed genes upregulated by PRDM16 overexpression in both $\mathrm{K} 1$ and BCPAP cell lines by RNA-sequencing. The top 30 co-upregulated 
genes were listed in List 2. (C) QRT-PCR confirmed the targeted genes mRNA expression level in 20 pairs of human PTC and normal thyroid tissues. PC was significantly overexpressed in human PTC tissues. (D) PC mRNA expression level in one normal thyroid cell line Nthy-ori-3-1 and three PTC cell lines, TPC-1, BCPAP and K1. The results were normalized to $\beta$-actin mRNA level. The relative quantification of PC expression in PTC cell lines was measured as fold to Nthy-ori-3-1 cell line. (E) Western blotting confirmed PC protein expression level in Nthy-ori-3-1, TPC-1, BCPAP and K1 cell lines. (F) Knock-down efficiency of PC in TPC-1 and K1 cell lines confirmed by qRT-PCR. (G) PC downregulation significantly inhibited cell proliferative ability of TPC-1 and K1 examined by CCK-8 assay. $(\mathrm{H})$ Knock-down of PC significantly inhibited cell migration ability of TPC- 1 and K1 examined by Transwell assay. ${ }^{*} \mathrm{P}<0.05,{ }^{\star} * \mathrm{P}<0.01$, $\star \star \star P<0.001$, data were pooled from three independent experiments. Abbreviations: PC: pyruvate carboxylase; PRDM16: positive regulatory domain containing 16; PTC: papillary thyroid cancer. 

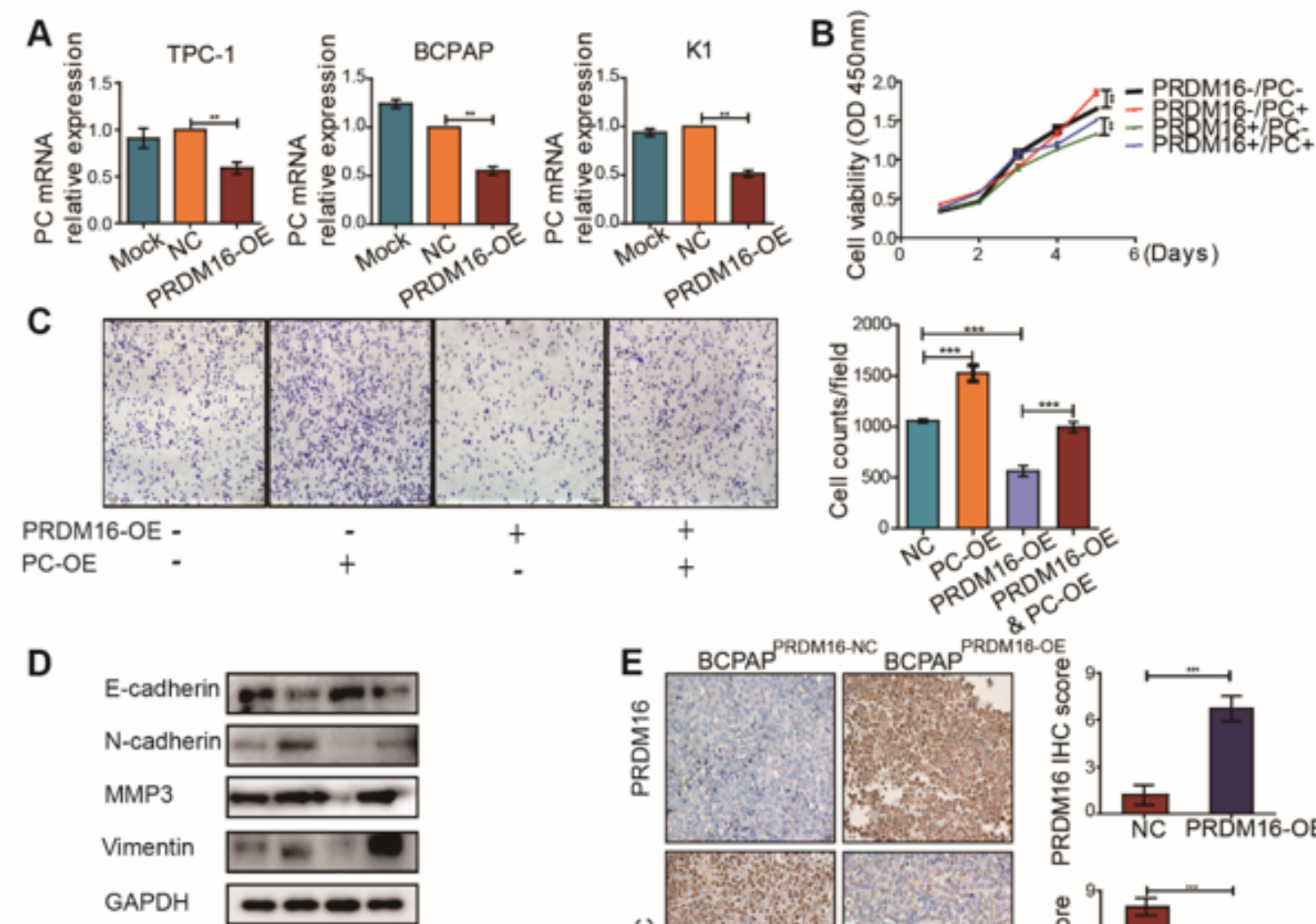

PRDM16-OE - - +++

PC-OE

F

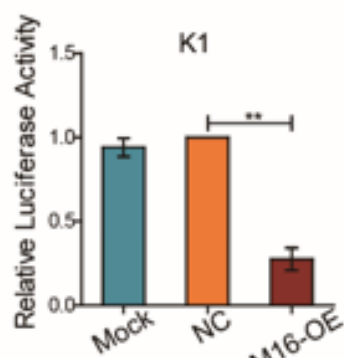

H

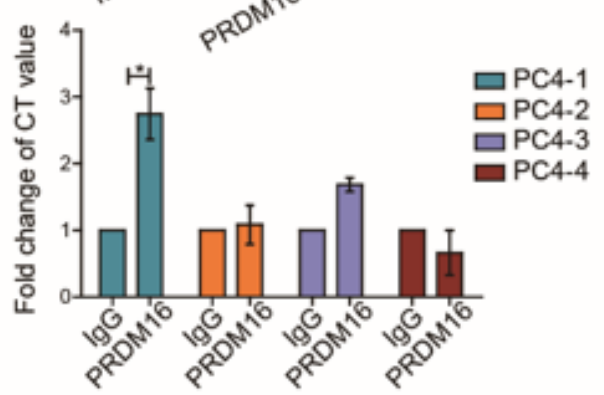

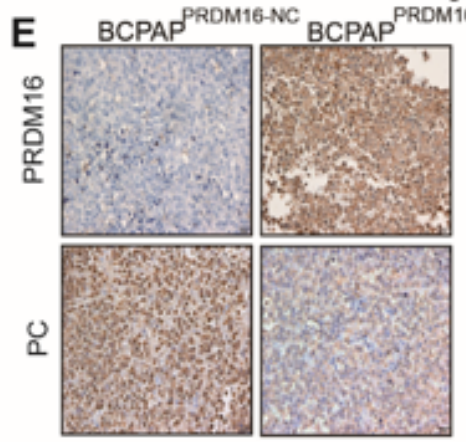
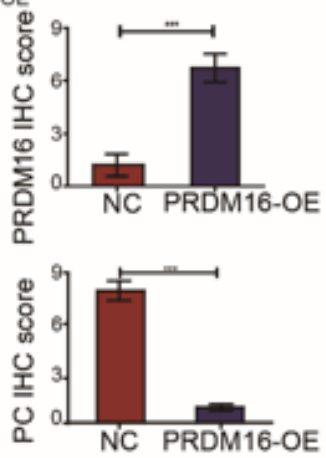

G

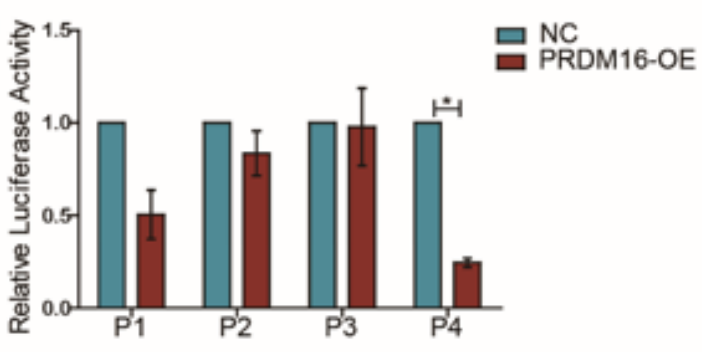

1

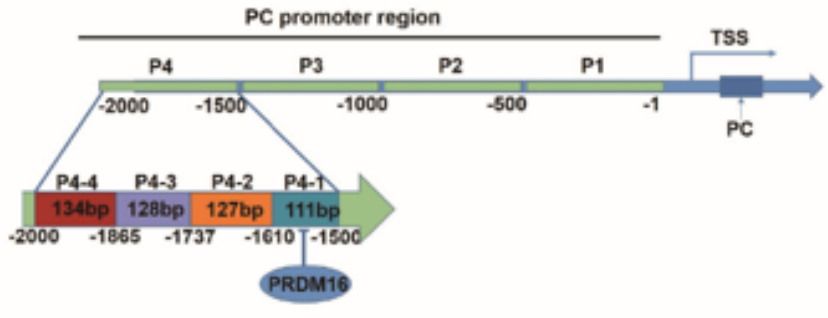

\section{Figure 4}

PC recovered the effect of PRDM16 and was regulated directly by PRDM16 at transcriptional level. (A) PC mRNA expression was significantly downregulated by PRDM16 overexpression. The relative quantification of PC expression was measured as fold to each normal PTC cell line. The results were normalized to $\beta$-actin mRNA level. (B) PC overexpression significantly promoted normal BCPAP cell proliferative ability. BCPAPPRDM16-OE cell line had a significant recover of proliferation after PC 
overexpression. The results were examined by CCK-8 assay. (C) PC overexpression significantly promoted normal BCPAP cell migrative ability. BCPAPPRDM16-OE cell line had a significant recover of migration by PC overexpression. The results were examined by Transwell assay. (D) PC overexpression promoted EMTrelated proteins expression in normal BCPAP cell line and recovered the inhibition of EMT-related proteins expression level in BCPAPPRDM16-OE cell line. (E) Representative IHC images showed successful upregulation of PRDM16 gene in BCPAPPRDM16-OE cell line in recipient mice PTC tissues. PC was expressed significantly negative in BCPAPPRDM16-OE PTC tissues compared with BCPAPPRDM16-NC PTC tissues. (F) Luciferase reporter assay in $\mathrm{K} 1$ cell line with PRDM16 enhancement. The relative quantification of luciferase activity was measured as fold to negative controls. (G) Luciferase reporter assay showed that PRDM16 bound to specific region of PC promoter in $\mathrm{K} 1$ cell line. The relative quantification of Luciferase activity was measured as fold to negative controls. (H) QRT-PCR results of ChIP analysis showed the direct binding of PRDM16 to PC promoter region. The relative quantification of CT value was measured as fold to IgG antibody as negative control. (I) The map of PRDM16 binding sits in the promoter region of $P C$. ${ }^{*} P<0.05,{ }^{*} P<<0.01,{ }^{*} * \mathrm{P}<0.001$, data were pooled from three independent experiments. Abbreviations: ChIP: chromatin immunoprecipitation; IHC: immunohistochemistry; PC: pyruvate carboxylase; PRDM16: positive regulatory domain containing 16; PTC: papillary thyroid cancer; TSS: transcription start site. 
A

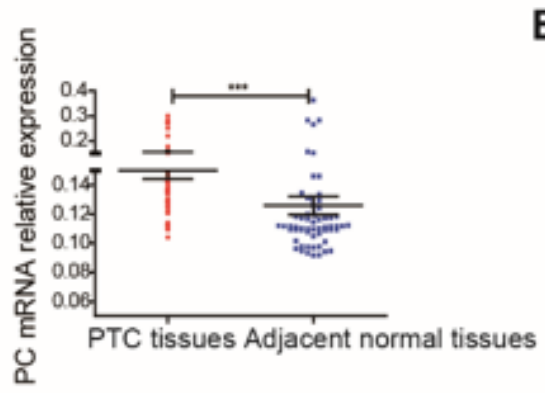

C

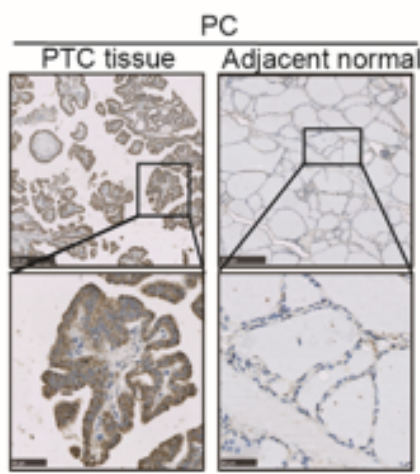

D

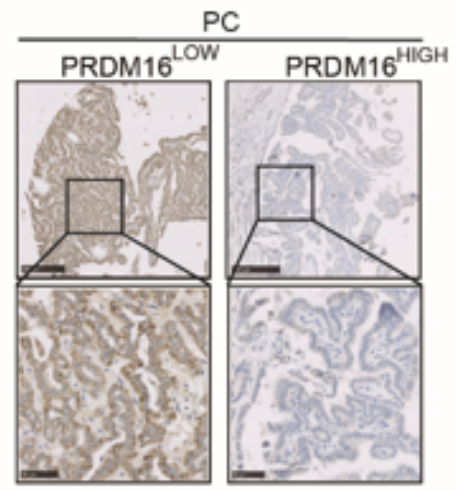

E

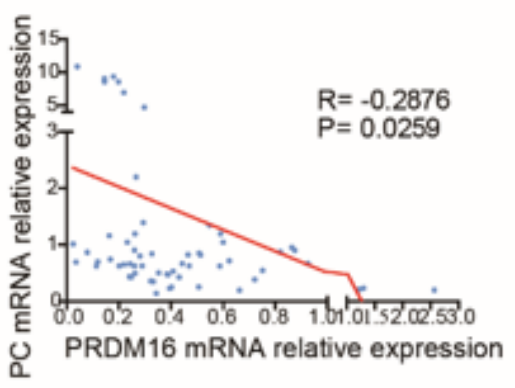

B $\Phi$
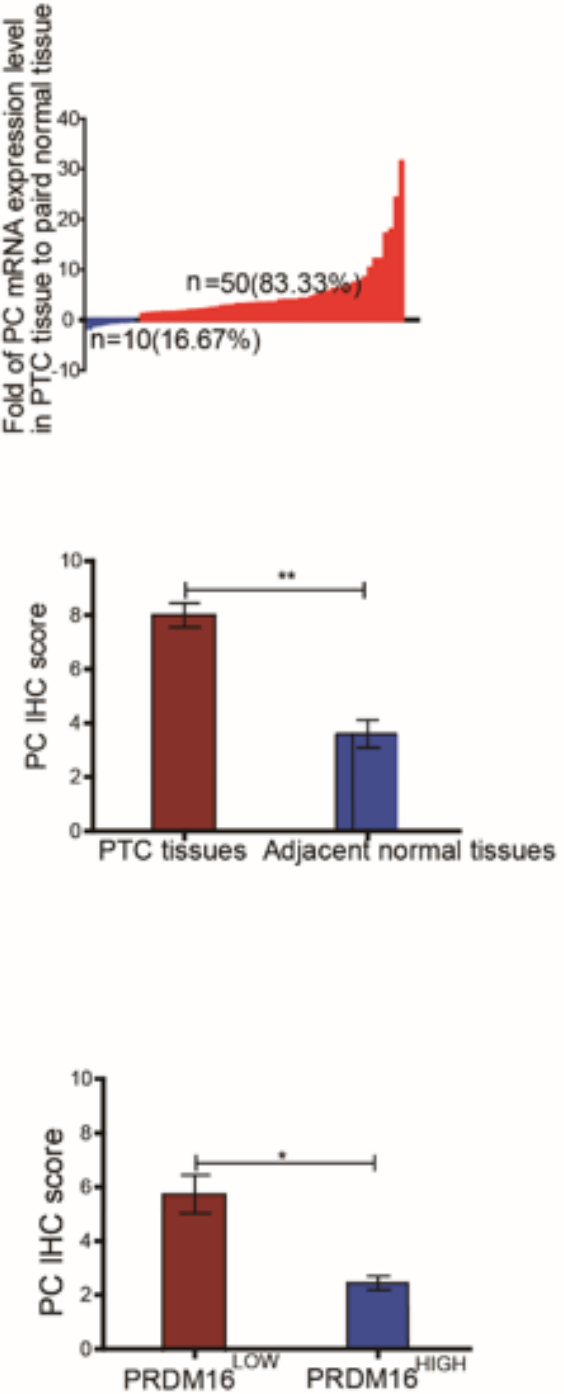

$\mathbf{F}$

MRNA Expression; RSEM (Batch normalized from Illumina HiSeq_RNASeqV2):PRDM16 vs. PC

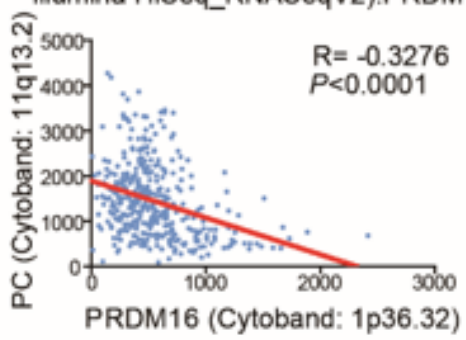

\section{Figure 5}

PC was lowly expressed in human PTC tissues and was negatively correlated with PRDM16 expression. (A) PC mRNA expression level between tumor and normal tissues in 60 PTC patients from FUSCC. The results were normalized to $\beta$-actin mRNA level. (B) Waterfall plot showed the distribution of PC expression level in each PTC patients from FUSCC. (C) IHC staining of PC expression in formalin-fixed, paraffinembedded PTC and corresponding non-tumor thyroid tissues (original magnification, x100, x400). PC 
was strongly positive in PTC tissues and almost negative in normal thyroid regions. (D) Representative IHC images showed PC expression of human PTC tissues in low and high PRDM16 expression levels (original magnification, $x 100, x 400$ ). (E) PC and PRDM16 mRNA expression level had significantly negative correlation by qRT-PCR in 60 PTC patients from FUSCC. (F) PC and PRDM16 mRNA expression level had significantly negative correlation in PTC patients from TCGA. ${ }^{*} P<0.05,{ }^{*} P<0.01,{ }^{*} *{ }^{*} P<0.001$ data were pooled from three independent experiments. Abbreviations: FUSCC: Fudan University Shanghai Cancer Center; IHC: immunohistochemistry; PC: pyruvate carboxylase; PRDM16: positive regulatory domain containing 16; PTC: papillary thyroid cancer; TCGA, The Cancer Genome Atlas.

\section{Supplementary Files}

This is a list of supplementary files associated with this preprint. Click to download.

- supplement5.pdf 